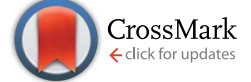

Cite this: Nat. Prod. Rep., 2016, 33, 988

\title{
The evolution of genome mining in microbes - a review
}

\author{
Nadine Ziemert, ${ }^{\star a b}$ Mohammad Alanjary ${ }^{\mathrm{ab}}$ and Tilmann Weber ${ }^{\star c}$
}

\author{
Covering: 2006 to 2016
}

The computational mining of genomes has become an important part in the discovery of novel natural products as drug leads. Thousands of bacterial genome sequences are publically available these days containing an even larger number and diversity of secondary metabolite gene clusters that await linkage to their encoded natural products. With the development of high-throughput sequencing methods and the wealth of DNA data available, a variety of genome mining methods and tools have been developed to guide discovery and characterisation of these compounds. This article reviews the development of these computational approaches during the last decade and shows how the revolution of next generation sequencing methods has led to an evolution of various genome mining approaches, techniques and tools. After a short introduction and brief overview of important milestones, this article will focus on the different approaches of mining genomes for secondary metabolites, from detecting biosynthetic genes to resistance based methods and "evo-mining" strategies including a short evaluation of the impact of the development of genome mining methods and tools on the field of natural products and microbial ecology.

Received 29th February 2016

DOI: $10.1039 / \mathrm{c} 6 \mathrm{np} 00025 \mathrm{~h}$

www.rsc.org/npr

\section{Introduction}

2. A short history of genome mining

3. Classical genome mining: search for enzymes involved in the biosynthesis of secondary metabolites

3.1 Mining for genes encoding core-biosynthetic enzymes

3.2 Polyketides

3.3 Non-ribosomally synthesized peptides (NRPs)

3.4 Ribosomally synthesized and post-translationally modified peptides (RiPPs)

3.5 Terpenoids/isoprenoids

3.6 Screening for tailoring enzymes

4. Comparative genome mining

5. Phylogeny based mining methods

6. Resistance/target based mining methods

7. Mining for regulators

8. Culture independent mining: single cells and metagenomes

9. Conclusions

10. Acknowledgements

11. References

anterfaculty Institute for Microbiology and Infection Medicine Tübingen (IMIT), Microbiology and Biotechnology, University of Tuebingen, Germany. E-mail: nadine. ziemert@uni-tuebingen.de

${ }^{b}$ German Centre for Infection Research (DZIF), Partner Site Tübingen, Germany

${ }^{c}$ Novo Nordisk Foundation Center for Biosustainability, Technical University of Denmark, Hørsholm, Denmark. E-mail: tiwe@biosustain.dtu.dk
The fast development of genome sequencing methods revolutionized almost every aspect of biology including natural product research. We have come a long way during the last three decades from the identification and manipulation of the first secondary metabolite genes to whole genome sequencing of thousands of bacterial genomes and metagenomes for a fast and automated discovery of promising new natural products and their role in the environment. With the wealth of genetic data available these days, there is no shortage of secondary metabolite gene clusters anymore; the challenge is now to effectively mine the data, connect whenever possible detected Biosynthetic Gene Clusters (BGC) to the vast amount of already known molecules and predict the ones that encode the most promising compounds. Plenty of tools are available to enable researchers to computationally mine genetic data and connect them to known secondary metabolites, and plenty of reviews are available that describe those tools and their applications. This review is focused on the development of genome mining methods over the last 10 years and the various strategies to detect and prioritize secondary metabolite gene clusters (Fig. 1). Rather than presenting extensive examples we focus on the rapid evolution of genome mining approaches and strategies and give some examples of when and how they were used for compound discovery, and which directions and challenges are remaining in the near future. 


\section{A short history of genome mining}

Drug discovery efforts have traditionally been based on bioactivity screening efforts of natural sources such as plants, fungi or bacteria. Bioactive isolated chemical structures, so called natural products or derivatives of those have been used as drug leads for new antibiotics, anticancer agents or immunotherapeutics. ${ }^{1,2}$ Ignited by the discovery of penicillin and streptomycin, the golden age of antibiotics began and researchers discovered microbial secondary metabolites as an important source for new antibacterial compounds. Today, natural products remain the main source for new therapeutic agents. The genus Streptomyces has especially been chemically exploited for decades in search for new drugs. ${ }^{3}$

With the establishment of Streptomyces genetics and the discovery of the first biosynthetic genes in the 70s and 80s, researchers started to understand the biosynthetic logic and genetic basis for the production of these compounds. ${ }^{4-8}$ Using classical genetics or reverse genetics approaches, it was possible to map and connect many biosynthetic gene clusters to known molecules. ${ }^{9-12}$

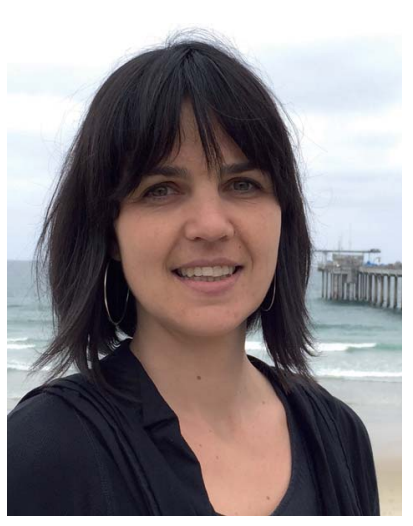

Nadine Ziemert received her Diploma and $P h D$ degrees from the Humboldt University in Berlin, followed by a postdoc and project scientist position at the Scripps Institution of Oceanography in La Jolla, California. Since 2015, she is a Professor at the University of Tübingen, where she leads an interdisciplinary research group focusing on genome mining approaches and the evolution of secondary metabolites in bacteria and their diverse functions.

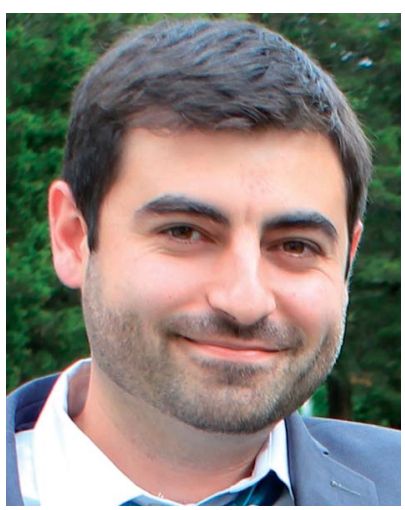

Mohammad Alanjary obtained a B.S. in Biochemistry/Chemistry at the University of California San Diego (UCSD) before moving to an enterprising gene sequencing company, Ion Torrent; there he aided in the launch of the first commercial semi-conductor gene sequencing platform and developed several procedures for the optimization of sequencing performance. His interest in programming new analysis methods to deal with the overwhelming genomic tsunami of today led him to work on his PhD in bioinformatics at the University of Tübingen, Germany.
Beginning with the new millennium and the full genome sequences of two well studied natural product producing strains Streptomyces coelicolor ${ }^{13}$ and Streptomyces avermitilis ${ }^{14}$ scientist noticed the unexplored potential hidden in bacterial genomes. A Streptomyces genome contains on average about 30 secondary metabolite gene clusters and only two or three were known at the time.

At this time the classical idea of genome mining was born: predicting and isolating natural products based on genetic information without a structure at hand. Inspired by the observation that even well studied strains contain the genetic potential to synthesize many more compounds than detected analytically, the genome mining concept was expanded to other microbes where genome information became available, such as cyanobacteria, ${ }^{39,40}$ myxobacteria, ${ }^{41-43}$ and anaerobes. ${ }^{44,45}$ Nowadays, thousands of bacterial genomes have become available, whole culture collections are currently being sequenced, and new technologies like single cell genomics and metagenomics generate massive data to be analyzed.

The current largest collection of automatically mined gene clusters is the "Atlas of Biosynthetic gene Clusters", a component of the "Integrated Microbial Genomes" Platform of the Joint Genome Institute (JGI IMG-ABC) ${ }^{46}$ As of February 2016, IMG-ABC contains entries for more than 960000 putative gene clusters identified in JGI's huge genome and metagenome datasets and public databases. However, only a very small fraction of these predicted BGCs are characterized and their products described. In a recent community effort within the "Minimum Information for Biosynthetic Gene clusters" (MIBiG) standardization initiative a manual re-annotation of $\sim 1300$ BGCs has been carried out now providing a highly curated reference dataset. ${ }^{47}$

\section{Classical genome mining: search for enzymes involved in the biosynthesis of secondary metabolites}

Mining for enzymes, or more precisely genes encoding enzymes putatively involved in secondary metabolite biosynthesis of

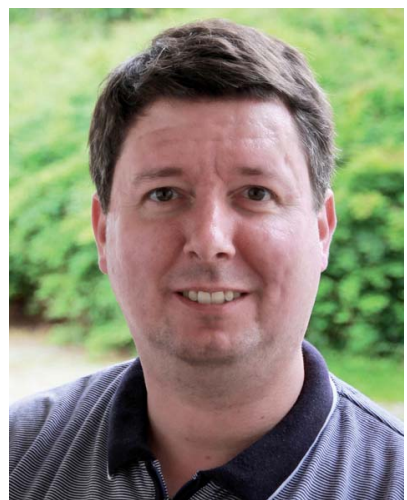

Dr Tilmann Weber is Co-Principal Investigator of the New Bioactive Compound section at the Novo Nordisk Foundation Center for Biosustainability of the Technical University of Denmark. He is interested in integrating bioinformatics, genome mining, and systems biology approaches into Natural Products discovery and characterization and thus bridging the in silico and in vivo world. He obtained his PhD (supervisor Prof. Dr Wolfgang Wohlleben) and his habilitation at the Eberhard Karls University Tübingen, Germany. 


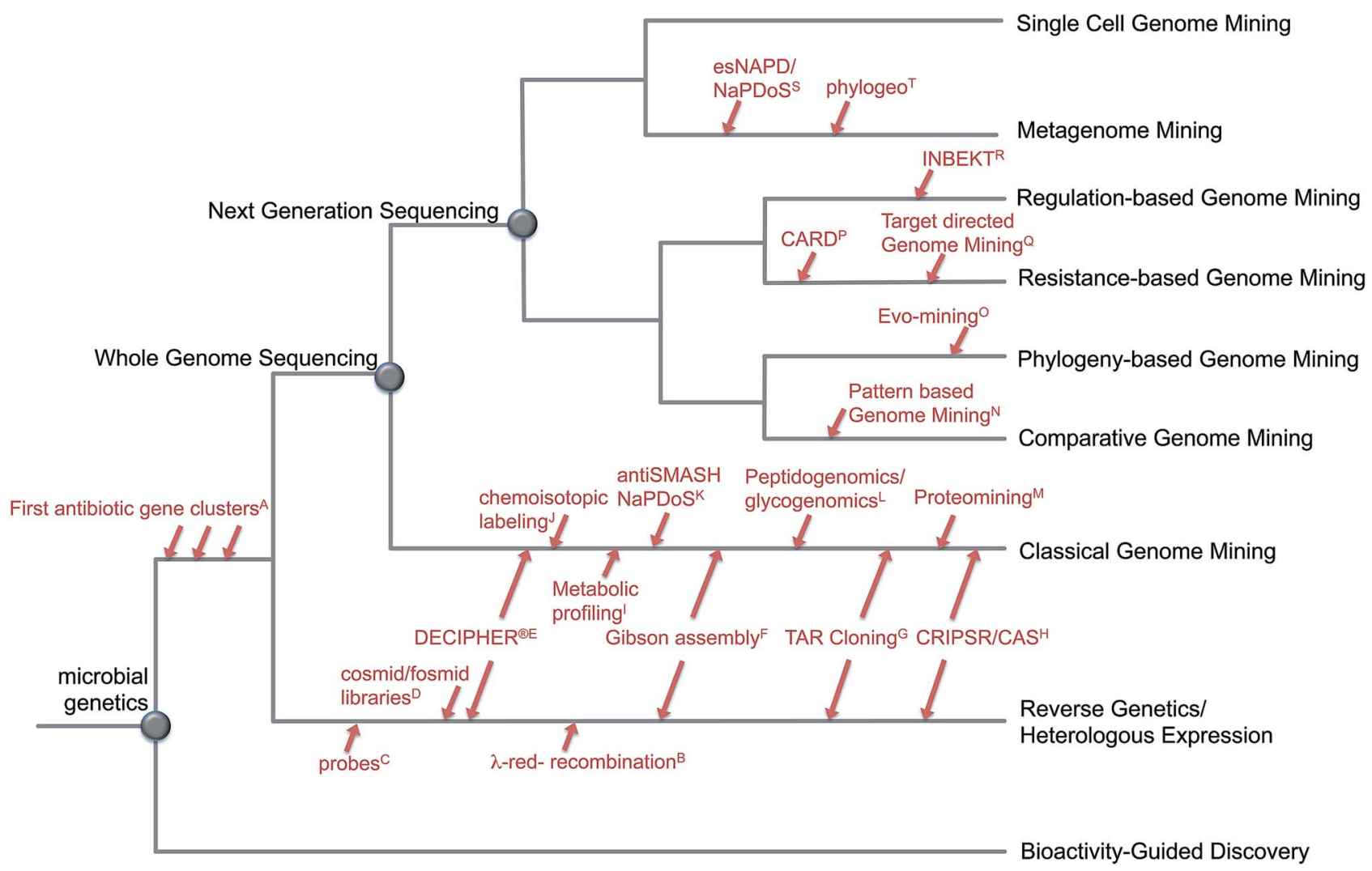

Fig. 1 Evolution of genome mining. Overview about approaches and strategies to mine microbial genomes for novel secondary metabolites

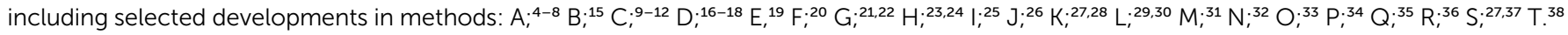

interest is the most "classical" variant of genome mining. Although the diversity of secondary metabolites is huge, the biosynthetic principles and thus the biosynthetic machineries for many of these compounds are often strikingly conserved. This is reflected in the high amino acid sequence similarity of many of the core biosynthetic enzymes. Examples for classes of secondary metabolites using such conserved machineries are polyketides (PK), biosynthesized by polyketide synthases (PKS), non-ribosomally synthesized peptides (NRP), produced by non-ribosomal peptide synthetases (NRPS), ribosomally and post-translationally modified peptides (RiPPs), aminoglycosides, and many more.

Even before large-scale genome sequence data were available, this sequence conservation was used in reverse genetics approaches to screen genetic libraries of producers for the presence of core biosynthetic genes. ${ }^{\mathbf{1 1}}$ Conserved genes of characterized pathways (or fragments, e.g., PKS or NRPS domains) were labeled and used as probes in Southern hybridization experiments. Alternatively, primers were deduced from highly conserved motifs of these genes and used for PCR screening approaches. With improved quality and throughput of sequencing and the massive decrease of costs, many of these approaches are currently carried out in silico instead of involving tedious generation of libraries and experimental screening. But the general principle behind the in silico mining is the same for reverse genetics: one or multiple sequences encoding "reference" enzymes are used as seed sequences to identify homologues in the genome sequences of the organisms of interest. For this task, sequence based comparison software, like BLAST ${ }^{48}$ or DIAMOND ${ }^{49}$ or profile-based tools like HMMer $^{50}$ are usually used. If the structure of the compound of interest is already known and a hypothetical biosynthetic route can be predicted, this approach often leads to an easy identification of the responsible biosynthetic gene cluster, as demonstrated for many pathways, for example: teixobactin, ${ }^{51}$ cypemycin, ${ }^{52}$ microbisporicin, ${ }^{53}$ ristomycin, ${ }^{54}$ microcyclamide, ${ }^{55}$ microviridin, ${ }^{56}$ poly(L-diaminopropionic acid), ${ }^{57}$ and many more. In the following sections, we are focusing on metabolites, in which the gene cluster was used as the starting point and the compound was not described before.

While mining for genes encoding conserved biosynthetic enzymes can, in principle, be easily done manually with BLAST or HMMer, integrated tools and databases were developed that greatly expedite this approach. To our best knowledge, the first reported tool for automated cluster mining was DECEIPHER ${ }^{\circledR}$, a proprietary pipeline and database developed around 2001 by the former company Ecopia Biosciences Inc. ${ }^{19}$ In the following years additional tools were developed and became freely available including BAGEL, ${ }^{58}$ CLUSEAN $^{59}$ and antiSMASH. ${ }^{28}$ To provide a comprehensive overview on such software and databases, the "The Secondary Metabolite Bioinformatics Portal" was recently launched at http://www.secondarymetabolites.org. The community-driven website provides a regularly updated and maintained catalogue of available secondary metabolism specialized software and databases and direct links to the 
Table 1 Examples of novel compounds identified by mining for core biosynthetic enzymes. Only examples where the BGC directed the identification of the novel metabolites are included

\begin{tabular}{llll}
\hline Compound name & Gene cluster ID (MIBiG)/Genbank & Means of identification & \\
\hline $\begin{array}{l}\text { Type I polyketides } \\
\text { Asperfuranone }\end{array}$ & & \\
Stambomycins & BGC0000022 & Search for PKS genes in A. nidulans whole genome sequence & 158 \\
Salinilactam & BGC0000151 & Search for modular PKS genes in . ambofaciens \\
& BGC0000142 & Search for PKS/NRPS domain sequences & 83 \\
& & (and other secondary metabolite biosynthesis related genes) & 85 \\
ECO-02301 & in Salinispora tropica CNB-440 & 80
\end{tabular}

\section{trans-AT polyketides}

Rhizopodin

BGC0001111

Search for PKS/NRPS genes in S. aurantiaca Sg a15 using pipeline ${ }^{96}$

Type II polyketides

Hexaricins

Genbank: KT713752

Search for type II gene cluster with antiSMASH 2 (ref. 77)

\section{Type III polyketides}

Isogermicidin

Genbank: AL645882

Gene: SCO7221

\section{NRPS}

Aureusimines

BGC0000308

Coelichelin

Poeamide

Orfamide

Viscosin-family lipopeptide

S. peucetius siderophores

Thanapeptin

\section{Hybrid PKS-NRPS}

Isoflavipucine/

dihydroisoflavipucine

Aspyridones

Pyranonigirin E

Haliamide

Carlosic acid, carlosic acid methyl ester

Agglomerin F

Mutanobactin

Clarepoxcin A-E

Landepoxcin A/B

RiPPs: lanthipeptides

Venezuelin

BGC0000563

Streptocollin

BGC0001226

Informatipeptin

BGC0000518
BGC0000325

BGC0001208

BGC0000399

Genbank: AM181176

Locus: PFLU_2552, 2553, 4007

Not publicly available

Genbank: CBLV010000330

Locus: BN844_0667-0664

\section{BGC0001122}

BGC0000959

BGC0001124

RefSeq: NC_013440

Locus: HOCH_RS34665-03960

Genbank: ACJE01000021

Locus: ASPNIDRAFT_176722

Genbank: ACJE01000021

Locus: ASPNIDRAFT 176722

Genbank: AE014133

Locus: SMU_1334-1349

BGC0001203

BGC0001202
Search for conserved NRPS genes in S. aureus and other

Staphylococcus strains

Search for NRPS genes in $S$. coelicolor M145

Search for NRPS genes in Pseudomonas poae RE*1-1-14

Search for NRPS genes in P. fluorescens Pf- 5

Search for NRPS genes encoding cyclic lipopeptides

Search for NRPS genes, analysis with NRPS-PKS ${ }^{162}$

Search for NRPS with PKS/NRPS predictor, ${ }^{96}$ NP.searcher ${ }^{70}$ and antiSMASH ${ }^{28}$

Identification of the hybrid PKS/NRPS gene with SMURF ${ }^{165}$

166

Search for hybrid PKS/NRPS genes

167

Search for hybrid PKS/NRPS genes; comparison with

168

pynA of A. niger CBS 513.88

Search for hybrid PKS/NRPS genes with antiSMASH ${ }^{28}$

169

Search for hybrid PKS/NRPS genes

Search for hybrid PKS/NRPS genes

170

Search for PKS and NRPS genes, analysis with NRPS-PKS ${ }^{162}$

171 and 172

Search for specific KS domain responsible for synthesizing the epoxyketone warhead ${ }^{173}$ with eSNAPD ${ }^{37}$ Search for specific KS domain responsible for

synthesizing the epoxyketone warhead ${ }^{173}$ with eSNAPD ${ }^{37}$

Search for genes encoding enzymes with N-terminal Ser/Thr kinase and C-terminal LanC-type domain

Search for lanthipeptide gene clusters

using antiSMASH 3 (ref. 78)

Combination of automated genome

mining for RiPPs and mass spectrometric

analysis using RiPPquest ${ }^{116}$
RiPPs: lasso peptides

Capistruin
BGC0000572
Search for homologues of microcin $\mathrm{J} 25$

biosynthetic genes $m c j B C D$
121 
Table 1 (Contd.)

\begin{tabular}{|c|c|c|c|}
\hline Compound name & Gene cluster ID (MIBiG)/Genbank & Means of identification & Ref. \\
\hline Caulosegnins & BGC0000574 & $\begin{array}{l}\text { Search for homologues of lasso peptide } \\
\text { biosynthetic enzymes (B-/C-proteins) }\end{array}$ & 174 \\
\hline Astexin-1 & BGC0000570 & $\begin{array}{l}\text { Search for conserved patterns in lasso peptide } \\
\text { precursor peptide using } \mathrm{MEME}^{175} / \mathrm{MAST}^{176}\end{array}$ & 177 \\
\hline Burhizin & BGC0000571 & $\begin{array}{l}\text { Search for homologues of lasso peptide } \\
\text { biosynthetic enzymes (B-/C-proteins) }\end{array}$ & 178 \\
\hline Caulonodins & BGC0000573 & $\begin{array}{l}\text { Search for homologues of lasso peptide } \\
\text { biosynthetic enzymes (B-/C-proteins) }\end{array}$ & 178 \\
\hline Rubrivinodin & BGC0000576 & $\begin{array}{l}\text { Search for homologues of lasso peptide } \\
\text { biosynthetic enzymes (B-/C-proteins) }\end{array}$ & 178 \\
\hline Sphingonodins & BGC0000577 & $\begin{array}{l}\text { Search for homologues of lasso peptide } \\
\text { biosynthetic enzymes (B-/C-proteins) }\end{array}$ & 178 \\
\hline Xanthomonins & BGC0000580 & $\begin{array}{l}\text { Search for homologues of lasso peptide } \\
\text { biosynthetic enzymes (B-/C-proteins) }\end{array}$ & 179 \\
\hline Chaxapeptin & BGC0001307 & $\begin{array}{l}\text { Search for homologues of B-protein LarB } \\
\text { (lariatin biosynthesis) }\end{array}$ & 180 \\
\hline \multicolumn{4}{|l|}{ RiPPs: cyanobactins } \\
\hline Microcyclamide PCC7806A/B & BGC0000474 & $\begin{array}{l}\text { Search for homologues of cyanobactin clusters in } \\
\text { M. aeruginosa PCC7806 }\end{array}$ & 55 \\
\hline Aeruginosamide & BGC0000483 & Search for cyanobactin gene clusters in cyanobacteria & 181 \\
\hline Viridisamide & BGC0000471 & Search for cyanobactin gene clusters in cyanobacteria & 181 \\
\hline \multicolumn{4}{|l|}{ Terpenoids/isoprenoids } \\
\hline Cembrane & Genbank: AB738084, AB738085 & $\begin{array}{l}\text { Blast search for homologs of CotB1, a } \\
\text { geranyl-geranyl diphosphate synthase } \\
\text { from cyclooctatin biosynthesis }\end{array}$ & 124 \\
\hline Kolavelools & $\begin{array}{l}\text { Genbank: ABX04785 } \\
\text { Locus: HAUR_2145, HAUR_2146 }\end{array}$ & $\begin{array}{l}\text { Blast search for homologs of Rv3377c } \\
\text { (diterpene cyclase) and Rv3378c (diterpene synthase) }\end{array}$ & 182 \\
\hline Stellatic acid & Genbank: LC073704 & $\begin{array}{l}\text { Search for homologs of AcOS, a sesterterpenoid synthase } \\
\text { from ophiobolin F biosynthesis }\end{array}$ & 183 \\
\hline $\begin{array}{l}\text { Hydropyrene, hydropyrenol, } \\
\text { and others }\end{array}$ & $\begin{array}{l}\text { Genbank: CM000914 } \\
\text { Locus: SCLAV_p0765 }\end{array}$ & $\begin{array}{l}\text { HMM-based search for terpene synthases; }{ }^{127} \\
\text { heterologous expression }\end{array}$ & 126 \\
\hline
\end{tabular}

respective tools and websites. ${ }^{60}$ As there have been multiple recent publications reviewing these tools, ${ }^{60-69}$ here we focus primarily on the application aspects. Several tools exist focusing on specific classes of secondary metabolite biosynthetic pathways, mostly PKS and/or NRPS ${ }^{70-74}$ or RiPPs. ${ }^{58,75,76}$ All these tools screen genomic data using profiles of known and highly conserved biosynthetic enzymes (e.g., PKS domains) and evaluate the results using pre-defined manually curated rules. The most comprehensive platform to perform such analyses currently is antiSMASH. ${ }^{28,77,78}$ In the current version 3.04, antiSMASH can identify 44 different gene cluster types based on hits against a library of enzymes/protein domains commonly observed in secondary metabolite biosynthetic pathways.

\subsection{Mining for genes encoding core-biosynthetic enzymes}

In the following section, several examples - from the beginning of genome mining, where most sequence analysis steps had to be carried out manually - until the present, where comprehensive bioinformatic software packages aid the scientists to identify novel compounds, are discussed for important families of bioactive secondary metabolites. A more extensive list of compounds, where genome mining has directly led to the identification of the metabolites, is included in Table 1.

\subsection{Polyketides}

Even before whole genome sequencing became a routine endeavor, genomics guided approaches were used to identify novel biosynthetic pathways and new molecules. One of the first approaches was published in 2003, when researchers of the company Ecopia Biosciences Inc. reported the identification of 11 new enediyne BGCs. ${ }^{25}$ Enediynes are interesting drug candidates as their high cytotoxicity makes them promising tools for antibody-drug conjugates to treat cancer. ${ }^{79}$ As it was not affordable at that time to simply sequence whole genomes of the studied actinomycetes, Zazopoulos et al. generated plasmid libraries of the producers. By Sanger sequencing of 1000 plasmids per library, they were able to generate $\sim 700 \mathrm{bp}$ long "sequence tags" covering the whole genome. The tags then were compared to sequences of genes involved in warhead formation of enediyne BGCs that were already known using Ecopia's DECIPHER® tool and database. Using this strategy, it was possible to identify 8 out of 50 strains that contain BGCs encoding enediyne biosynthesis pathways. Although no analytical proof of enediyne formation was provided in the original work, results of prophage induction assays indeed indicated that all of these strains have the potential to produce DNA damaging agents (as the enediynes are). ${ }^{25}$ A similar 
strategy was also applied to identify the antifungal agent ECO02301, which is biosynthesized via a modular type I PKS complex. ${ }^{80}$

With the easy and cheap availability of whole genome sequence data, many other gene clusters have been identified and associated with chemical products. One noteworthy example is the polyketide stambomycin. In the course of the analysis of the Streptomyces ambofaciens genome, which was known to code for the congocidine and spiramycin biosynthetic gene clusters, ${ }^{81,82}$ a $150 \mathrm{~kb}$ gene cluster was identified, which codes for 25 genes, among them 9 encode type I PKS, making this one of the largest PKS gene clusters known so far. ${ }^{83}$ The analysis with the software SEARCHPKS ${ }^{84}$ indicated that the PKS genes code for 112 enzymatic domains organized in 25 PKS modules, including a $\mathrm{KS}^{\mathrm{Q}}$ domain at the starter module and a TE domain at the last module. Based on the domain organization, specificity predictions for the AT domains and stereochemistry predictions of KR domains the authors were able to predict a planar structure of the PK product synthesized by the PKS - with only one ambiguity as the substrate for the AT of module 12 (corresponding to the PK-unit C-25-C-26) could not be predicted. A transcriptional analysis revealed that this gene cluster was not expressed under normal laboratory growth conditions. However Laureti et al. were able to activate the expression by constitutively expressing samR0484, a LuxR-type regulator. With this engineered strain it was now possible to isolate the biosynthesis product stambomycin and perform an NMR-based structure elucidation. The experimentally determined structure of stambomycin was in very good accordance with the theoretically predicted product of the PKS. However, several features were not predicted in silico: the NMR studies revealed that at position $\mathrm{C}-26$ of the polyketide (corresponding to the ambiguous AT in module 12) extender units with diverse sidechains are used (leading to stambomycins A-D) and thus explains the lack of predictions for this module. In addition, the sites of macrolactonization, glycosylation and hydroxylations could not be predicted only based on the sequence analysis. ${ }^{\mathbf{8 3}}$ However, this work nicely demonstrates the power of the genome mining approach and that genome sequence data can be used to predict structures of secondary metabolites.

A nice example where genetic data and structural data go hand in hand is the polyene macrolactam salinilactam. The salinilactam gene cluster is the biggest gene cluster that was detected by bioinformatic analysis in the Salinispora tropica CNB440 genome. ${ }^{85}$ The high sequence identity and the repetitive nature of the various modules made correct assembly and closure of the genome problematic. However, based on characteristic UV chromophores the compound could be detected and initial structure elucidations suggested a 10-module PKS enzyme responsible for the biosynthesis of the compound, which facilitated assembly and therefore closure of the genome. The subsequent bioinformatic analysis of the AT domains on the other hand facilitated the final structure elucidation of the compound. This example aided the discovery of a whole family of macrolactams by implementing a "molecules-to-genes-to-molecules" approach by Schulze et al., who where able to detect the lobosamides and mirilactams by comparative genomic analysis. ${ }^{86}$
One important group of PKS enzymes are the trans-AT PKSs. ${ }^{87,88}$ These owe their name due to the lack of AT domains in each module; instead they encode one or more AT domains in trans, usually within each BGC. Genome mining efforts have shown that this group of enzymes is wide spread in bacteria, especially in chemically less studied genera. ${ }^{89}$ trans-AT PKS systems have evolved independently from cis-AT $\mathrm{PKSs}^{\mathbf{9 0}}$ and often include unusual biosynthetic enzymes leading to unique chemistry. Therefore, trans-AT PKS have been targeted by genome mining strategies in the past and led to the discovery of new compounds such as thailandamides, ${ }^{\mathbf{9 0}}$ rhizopodin $^{\mathbf{9 1}}$ or tolytoxin..$^{92}$ For an in depth review about these systems, we refer to Helfrich et al. ${ }^{\mathbf{8 8}}$

Mining for PKS core enzymes is not restricted to cis-AT and trans-AT modular type I PKS; the technique can also be highly efficiently applied for other types of PK pathways: using the antiSMASH software, 20 gene clusters were predicted in the rare actinomycete Streptosporangium sp. CGMCC 4.7309, among them the hex-cluster coding for a type II PKS. ${ }^{93}$ Phylogenetic analyses indicated that the gene product of hex23, which encodes the KS $\beta$ of the type II PKS, can be assigned to a group of pathways producing pentangular polyphenols. Indeed, Tian and colleagues were able to detect and elucidate a new family of polyketides, named hexaricins and experimentally confirmed by gene knock-out that the gene cluster identified is responsible for the biosynthesis of the compound.

In the case of type II PKS pathways, the consideration of phylogenetic data can give more accurate predictions on the putative products on metagenomic datasets ${ }^{94}$ (for details, see Section 5).

\subsection{Non-ribosomally synthesized peptides (NRPs)}

The high degree of conservation of the core-enzymes involved in NRP biosynthesis, the good co-linearity of the modular domain organization of NRPS enzymes with their biosynthetic products, the possibility to predict substrate specificities, e.g. using software like NRPSpredictor, ${ }^{71,72}$ SEQL-NRPS ${ }^{95}$ or other A-domain specificity predictors $^{96-98}$ have made this family of secondary metabolites interesting candidates for genome mining approaches. ${ }^{\mathbf{9 6 9 9}}$ This is further supported by the availability of cheminformatic approaches like MS/MS networking ${ }^{29,100}$ or iSNAP ${ }^{101}$ that allow the automatic mapping of identified and in silico analyzed NRP (and RiPP) BGCs to mass spectrometric data..$^{73,101-104}$

Genome mining, for example, led to the identification of NRP secondary metabolites also from organisms, such as Staphylococcus aureus, ${ }^{105}$ which usually are not regarded as prolific secondary metabolite producers. In the case of the biosynthesis of the siderophore coelichelin from the model actinomycete Streptomyces coelicolor M145, genome mining revealed new biochemical insights about NRPS biochemistry. The coelichelin pathway, which was identified in the S. coelicolor genome by searching for NRPS-like genes, codes for a 3module NRPS, but was experimentally confirmed to generate a tetrapeptide, ${ }^{\mathbf{1 0 6}}$ indicating exceptions of the co-linearity rule.

In a global view, mining for genes encoding NRPS or NRPSrelated enzymes has revealed a wide distribution of these 
pathways in Bacteria and Eukarya. In a comprehensive study by Wang et al. ${ }^{\mathbf{1 0 7}}$ more than 3300 BGCs coding for more than 16500 NRPS(like) enzymes have been identified. Interestingly, a significant number of the in silico identified enzymes do not follow the classical modular organization of NRPSs. Only few of these pathways have currently been studied experimentally, for example the pathway for congocidin biosynthesis. ${ }^{81}$ This makes it very challenging to interpret these BGCs and develop bioinformatics algorithms to predict their products.

\subsection{Ribosomally synthesized and post-translationally modified peptides (RiPPs)}

Lanthipeptide/lantibiotics have also been subject to successful genome mining approaches. One of the first examples, where the identification of the biosynthetic gene cluster preceded the discovery of the compound is lichenicidin. ${ }^{108}$ Begley et al. used PSI-BLAST to mine publicly available microbial genome sequences for homologues of the LanM lanthipeptide dehydratase/cyclase, which catalyzes the dehydration and cyclization of the lanthipeptide prepeptide using the sequence of LtnM1 involved in lacticin 3147 biosynthesis as query. Using this strategy, they were able to identify 89 strains. 61 of these strains were not previously described as lanthipeptide producers. Among these hits was Bacillus licheniformis ATCC 14580, which inhibited growth of Gram-positive bacteria, including L. monocytogenes, methicillin resistant $S$. aureus and vancomycin resistant enterococci. Indeed a lanthipeptide named lichenicidin, which had the predicted molecular weight could be identified with mass spectrometry, isolated and re-tested demonstrating that it caused the antibacterial effect.

Another interesting example is the lanthipeptide venezuelin. ${ }^{109}$ When analyzing the draft genome sequence of $S$. venezuelae, a novel type of lanthionine cyclase/dehydratase named VenL was identified, which was composed of an Nterminal serin/threonine kinase instead of the dehydratase present in LanM/type II lanthipeptide biosynthesis pathways, and a C-terminal LanC domain. Although it was not possible to isolate a lanthipeptide from $S$. venezuelae, the authors were able to express and purify VenL in $E$. coli and demonstrate its activity as lanthionine synthase in vitro using synthesized peptides. ${ }^{109,110}$ Using the datasets of Doroghazi et al., ${ }^{111}$ only recently it was possible to identify further Streptomyces strains that possess BGCs that are similar to the venezuelin gene cluster. ${ }^{12}$ HPLC-MS analyses indicated, that some of these strains indeed produce venezuelin or closely related derivatives. The latest member of the venezuelin family of lanthipeptides is streptocollin, which was identified via antiSMASH-based genome mining of $S$. collinus Tü $365 .{ }^{\mathbf{1 1 3}, 114}$ This strain only produces traces of streptocollin under the tested laboratory conditions. However, by expressing the streptocollin biosynthesis genes under control of a constitutive promoter in $S$. collinus Tü 365 or by heterologously expressing the gene cluster in the optimized expression host $S$. coelicolor M1152, ${ }^{115}$ preparative amounts of streptocollin could be obtained. While no significant antibacterial or antiviral activity was detected for streptocollin, a moderate inhibitory activity towards protein- tyrosine-phosphatase $1 \mathrm{~B}$, a potential target to treat type 2 diabetes or obesity, was observed. ${ }^{\mathbf{1 1 3}}$

Similar to NRPs, the combination of genome mining with computational mass spectrometry approaches provides valuable tools for the identification of novel compounds. ${ }^{103,116}$ One of the first peptides identified with this method was the type III lanthipeptide informatipeptin produced by Streptomyces viridochromogenes DSM 40736. ${ }^{116}$

Lasso peptides are another very interesting family of RiPPs where genome mining has contributed much knowledge. Like most RiPPs, biosynthesis of lasso peptides starts with the ribosomal synthesis of a precursor peptide (A-peptide). This precursor is post-translationally modified by an ATP-dependent cysteine protease (B-protein), which cleaves-off the leader peptide, and an ATP-dependent asparagine synthetase B-like protein (C-protein), which catalyzes the lactam formation between the N-terminal amino group and the side chain of an aspartate or glutamate residue in the peptide leading to a cyclized molecule. The latter reaction is catalyzed in a way such that the C-terminal peptide tail is placed inside the ring thus leading to the name-giving lasso structure. This structure is usually stabilized by bulky plug residues of the peptide tail that prevent the slip-out and disulfide bonds that stabilize the structure. ${ }^{117}$

The first gene cluster of a lasso peptide was microcin J25 of $E$. coli AY25, ${ }^{118-120}$ where it was demonstrated that the precursor peptide along with the genes $m c j B$ and $m c j C$, which code for the B- and C-proteins respectively, are responsible for microcin J25 biosynthesis. In addition, the microcin J25 gene cluster contains $m c j D$, which codes for an $\mathrm{ABC}$ transporter that is involved in conferring immunity. In the first genome mining study that targeted novel lasso peptides, the sequences of $\mathrm{McjB}$, $\mathrm{McjC}$ and McjD were used as in silico probes to mine genomic databases. Knappe et al. ${ }^{\mathbf{1 2 1}}$ were able to detect genes coding for homologous enzymes in the genome sequence of Burkholderia thailandensis E264. In a manual reinvestigation of the DNA sequence upstream of the identified homologs the authors could identify an un-annotated open reading frame that was proposed to encode the precursor peptide. Indeed, the authors were successful in detecting traces of the predicted lasso peptide, named capistruin, in culture extracts of the strain. By optimizing the fermentation media and purification procedure, it was possible to obtain capistruin yields of $0.7 \mathrm{mg} \mathrm{L}^{-1}$, which provided sufficient amounts to confirm the structure of capistruin via NMR-based methods. Finally, it was possible to clone the capistruin BGC comprising of capABCD and express the pathway in $E$. coli with yields of $0.2 \mathrm{mg} \mathrm{L}^{-1}$, which is $\sim 30 \%$ of the $B$. thailandensis wild type yield. ${ }^{121}$ In the meantime, many additional lasso peptide biosynthetic gene clusters have been identified by genome mining (Table 1 ). Similar approaches have also been carried out for other classes of RiPPs, for example thiazole/oxazole modified microcins (TOMMs). ${ }^{112}$

\subsection{Terpenoids/isoprenoids}

With almost 400 distinct structural families comprising in total more than 55.000 described compounds, terpenoid/isoprenoid 
secondary metabolites are one of the largest class of bioactive metabolites, many produced by plants, fungi and also bacteria. ${ }^{122}$ The core units of terpenoids are assembled from a varying number of linked isoprene units (catalyzed by terpene synthases) that can undergo a multitude of intramolecular cyclizations, catalyzed by terpene cyclases, often followed by extensive tailoring steps. Although terpene synthases/cyclases are often not as highly conserved as, for example, NRPS or PKS it is possible to use individual characterized sequences as probes. Using these strategies, a variety of isoprenoids have been firstly identified and characterized by genome mining, e.g., the monoterpene cineolole, ${ }^{123}$ the diterpene cembrane, ${ }^{124}$ or the sesterterpene stellatic acid. ${ }^{125}$

To cover a wide sequence space and to identify more distantly related enzymes, a profile-HMM-based approach, that uses HMM-profiles trained with 140 bacterial terpene synthases, was also successfully used to screen novel pathways and identify a diverse set of new terpenoids. ${ }^{126,127}$

\subsection{Screening for tailoring enzymes}

Currently, most genome mining approaches focus on identifying core biosynthetic enzymes in genomic or metagenomic data. ${ }^{128}$ However, also so-called tailoring enzymes, that are involved in modifying precursor molecules, can be valuable targets to identify new BGCs. Already in the pre-genome mining era, reverse genetics approaches have been carried out to identify, for example, pathways encoding halogenases. ${ }^{129}$

With the availability of whole genome sequences, this strategy has expanded in silico. For example, sequences of bacterial desaturases/acetylenases were used as genome mining probes to identify biosynthetic gene clusters synthesizing compounds containing very rarely found alkyne groups. ${ }^{130,131}$ Other examples are the identification of BGCs encoding the biosynthesis of epoxyketone biosynthetic pathways in metagenomic datasets that led to the discovery of the clarepoxcins and landepoxcins, potent $20 \mathrm{~S}$ proteasome inhibitors. ${ }^{132}$

\section{Comparative genome mining}

"Classical" genome mining, i.e. the specific search for genes encoding enzymes involved in the biosynthesis of secondary metabolites in (meta)genomic sequences, and sophisticated software aiding the scientists for this task, were one of the main innovations within the history of natural products research in the recent years. ${ }^{64,133}$ The method can be further refined by not only focusing on single genes, but on partial or complete gene clusters. This functionality is, for example, included in the software antiSMASH, ${ }^{78}$ which can compare the identified BGCs in usersubmitted genomes with a huge collection of BGCs of other microorganisms and the curated MIBiG database, ${ }^{47}$ and thus indicate whether there are similar pathways in other organisms. The MultiGeneBlast algorithm, that provides such information, is also available as a stand-alone software, ${ }^{134}$ which can be used to identify similar gene clusters/operons for any given sequence.

Another approach to assess novelty of identified BGCs is to use Genome Neighborhood Networks (GNNs), ${ }^{135}$ which are

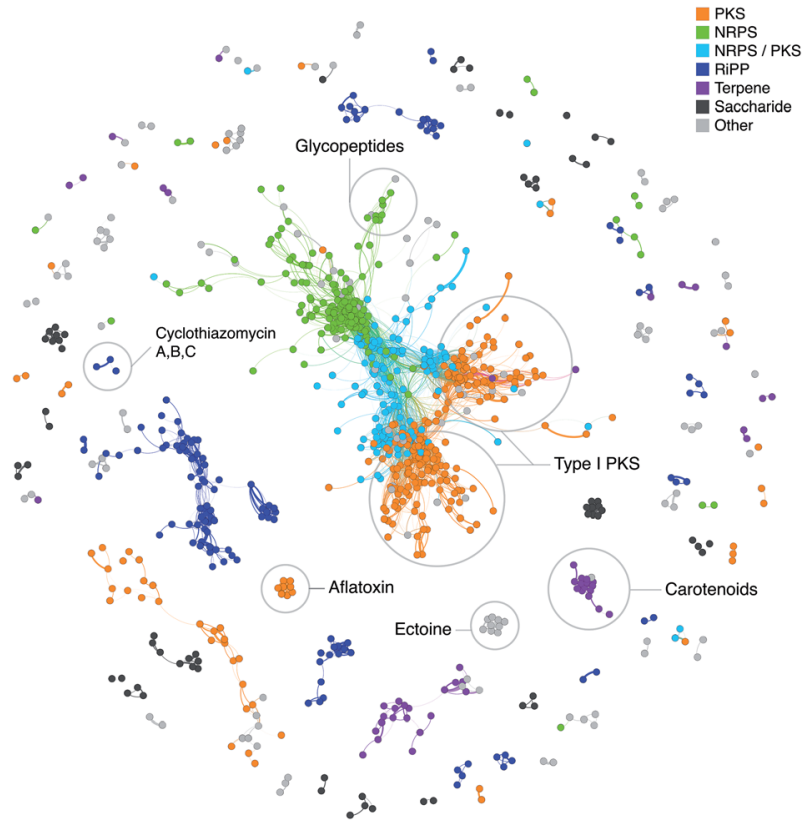

Fig. 2 Network of known BGCs from the MIBiG database ${ }^{47}$ using Pfam composition similarity. Distances were calculated with an adapted Jaccard and domain duplication index ${ }^{149}$ with a threshold of 0.5 and clustered in Gephi ${ }^{156}$ using the Yifan Hu method. ${ }^{157}$ Colored regions depict gene cluster type with examples of known compounds circled based on MIBiG annotations.

extended variants of sequence similarity networks ${ }^{136}$ (Fig. 2) that also take into account the neighborhood of the "target" gene. Such a study has recently been carried out to comprehensively study enediyne biosynthetic pathways and provide means for in silico prioritization. ${ }^{137}$

Although targeted genome mining approaches are very powerful and have led to the identification of new compounds and associations between biosynthetic pathways and molecules, they have one important limitation. As this approach requires sequences of known homologous enzymes or explicitly defined rules on what is considered a BGC, the results are limited to known biosynthetic types and families. Often, a difficult task is to connect new structural classes of compounds to their respective BGCs. Once the BGC and biochemistry is identified, homologous clusters and corresponding compounds can be detected in other organisms as well. A powerful example for this is the patellamide family of compounds. ${ }^{138}$ These highly modified cyclic peptides have been isolated from the marine ascidian Lissoclinum patella and were shown to be produced by cyanobacterial symbionts. ${ }^{139}$ Due to their highly modified amino acids, they were suspected to be produced by an NRPS dependent machinery for a long time. In contrast, Schmidt and colleagues were able to link the production to a class of ribosomal pathways ${ }^{140}$ later called cyanobactins that added to the great variety of RiPP pathways and led to the discovery of many more related molecules. ${ }^{141-143}$ Similarly, the microviridin BGCs have been discovered. ${ }^{56}$ These tricyclic peptides are biosynthesized by previously unknown classes of ATP grasp domain containing enzymes ${ }^{56,144,145}$ which were shown to be wide spread within free-living cyanobacteria. ${ }^{146,147}$ 
One approach to find unknown types of biosynthetic gene clusters more systematically was recently reported by Takeda et al. ${ }^{148}$ The algorithm used to identify BGCs in filamentous fungi is based on identifying homologous and orthologous genes in related species, and evaluate syntenic and non-syntenic regions. Unfortunately, the implementation of the algorithm or a web server is not yet publicly available.

Another strategy was developed by Cimermancic et al. ${ }^{149}$ The ClusterFinder algorithm uses a two-state hidden Markov model trained on strings of contiguous Pfam domains identified in 677 validated gene clusters (BGC state) and strings of Pfam domains of random genome regions (non-BGC state). This probabilistic model then was used to screen 1154 prokaryotic genomes, leading to the identification of more than 33000 putative BGCs, 10700 of the hits with high confidence scores. The most abundant class of biosynthetic gene clusters identified in this study were saccharides, which comprised $40 \%$ of all hits. This was unexpected as this class of molecules is only represented with $13 \%$ of the validated test data set and thus indicates a huge potential for finding new molecules. A global similarity analysis of the high-confidence hits revealed several "cliques"/families of BGC that have not yet experimentally studied so far. Experimental studies on selected members of this family (comprising 811 BGCs) revealed that one family codes for the biosynthesis of aryl polyene lipids. ${ }^{149}$ ClusterFinder was also used in a study analyzing data from the Human Microbiome Consortium. ${ }^{150}$ In the human microbiome, saccharide and RiPP gene clusters were also observed frequently, whereas NRPS and PKS gene clusters were significantly depleted. ${ }^{151}$ Based on these data, Donia et al. were able to identify a novel thiopeptide (RiPP) lactocillin, associate it with the corresponding BGC, and demonstrate that the biosynthesis pathway is actually transcribed in the human body. ${ }^{150}$

In a large-scale genome mining approach for type I and II polyketides, NRPS, NRPS-independent siderophores, lanthipeptides and TOMMs in more than 800 actinobacterial genomes Doroghazi et al. ${ }^{152}$ were able to identify more than 11000 gene clusters which could be grouped into 4122 gene cluster families (GCFs). The GCF network was calculated based on the combination of three distance metrics on the number of shared homologous genes, the proportion of nucleotides involved in pairwise alignment and the amino acid sequence identity of domains of modular enzymes. 77 of these GCFs included at least one already known and characterized gene cluster. Based on these, the authors identified 1193 uncharacterized gene clusters in a subset of 344 genomes, which likely code for the biosynthesis of novel derivatives of known compounds. The GCF network then was correlated with largescale high-resolution liquid chromatography/mass-spectrometry data of a subset of 178 strains allowing the link between metabolites and gene clusters. ${ }^{152}$ These datasets now are a valuable source for further studies, such as a global analysis of lanthipeptide biosynthetic pathways ${ }^{112}$ (see above).

These and other recent examples nicely demonstrate that especially combining genome mining with metabolomics/cheminformatics approaches, i.e. the automatic evaluation of mass spectrometric data using peptide- or glycogenomics, ${ }^{29,30}$ molecular networking, ${ }^{100}$ self-organizing metabolomic maps, ${ }^{153}$ or comprehensive MS/MS fragment databases, provide very powerful tools to identify novel secondary metabolites. ${ }^{32,102,103,116,154,155}$

\section{Phylogeny based mining methods}

The idea of comparing multiple bacterial genomes to detect and prioritize gene clusters is strongly connected to the idea of using phylogenetic methods to find promising secondary metabolite genes. As Dobzhansky stated: "Nothing in biology makes sense except in the light of evolution". ${ }^{184}$ Understanding how nature creates the amazing structural diversity of chemicals observed and appreciated by natural product chemists is not just a basic research question, but gives important insights into bioprospecting efforts, ecological function of these molecules and synthetic biology approaches.

The often modular structure of secondary metabolite gene clusters rendered the idea of a rapidly evolving defence system that develops new molecules by randomly shuffling and swapping domains and modules and develops analogous to an adaptive immune system. ${ }^{185}$ The first phylogenetic studies with selected PKS and NRPS systems clearly showed significant amounts of homologous recombination and gene duplication. ${ }^{186-189}$ Most of these studies, however, are limited case studies that include only a few related gene clusters that code for very similar molecules. The limited amount of data available at the time and the intensive computational demands on phylogenetic algorithms impeded more systematical analysis. With the diversity of tools for genome mining available now, more systematic approaches to infer the evolutionary history of nature's chemistry are available. One recent analysis of the evolution of about 10000 biosynthetic gene clusters revealed significantly higher rates of insertions, deletions and duplications in secondary metabolism compared to primary metabolism and demonstrated how successful nature mixes and matches sub-clusters to produce novel chemistry. ${ }^{190}$

Evolution and phylogenetic approaches have been used to guide genome mining efforts for a couple of years now. Two major approaches can be distinguished in natural product research. ${ }^{191,192}$ One uses species trees of natural product producing organisms based on conserved housekeeping genes or core genomes, and maps compound production subsequently on the tree. This way, talented chemistry producing lineages can be traced to develop more efficient sampling, isolation and genome mining techniques. ${ }^{193}$ The genome mining of 75 closely related Salinispora strains for example revealed major differences in the metabolic diversity of the three distinct species within the genus, proving S. pacifica as the most diverse compared to its sister taxa S. tropica and S. arenicola. ${ }^{194}$ In contrast, another study that compared secondary metabolite gene cluster diversity within the Streptomyces species $S$. pratensis revealed no differences in natural product BGCs, even when isolated from various distant geographic locations. ${ }^{195}$ An improved understanding of these phylogenetic patterns can guide bioprospecting efforts, especially in combination with the discovery of new families and clades within bacteria through directed cultivation efforts ${ }^{51}$ or metagenomic sequencing. ${ }^{196}$ 
However, species patterns and taxonomical correlations have to be interpreted carefully considering the tremendous amount of horizontal gene transfer, which proves to play a vital role in the evolution of secondary metabolites. ${ }^{\mathbf{1 8 9 , 1 9 0 , 1 9 4 , 1 9 7}}$ A second approach uses gene trees of secondary metabolite genes directly. These gene trees infer the evolutionary history of biosynthetic genes and gene clusters, and can often be used to infer biosynthetic functions of the enzymes more precisely than simple sequence similarity approaches. ${ }^{198,199}$

For more in depth information about evolution and the use of phylogenetic methods of natural products, we refer to other reviews. ${ }^{191,192}$ Here we focus on examples of phylogeny based mining techniques. Ketosynthase (KS) domains in PKS gene clusters have been one of the first enzyme families where phylogenetic trees have been used to predict structures. Instead of sequencing full genomes, at a time when this was not even yet feasible, degenerated primers were constructed and amplified PCR products sequenced. ${ }^{\mathbf{1 8 6 , 2 0 0 , 2 0 1}}$ Based on the phylogeny of these short sequence tags compound families and structures could be predicted. If characterized known KS domains claded closely with amplified PCR products, lineages without any known characterized KS domain indicated unknown or novel chemistry.

This concept was further developed by the Natural Product Domain Seeker (NaPDoS), a bioinformatic pipeline that allows the automated detection of KS and C domains from NRPS and PKS gene clusters and subsequently constructs a phylogenetic tree to infer novelty and potential of secondary metabolites from bacterial genetic data. ${ }^{27} \mathrm{NaPDoS}$ works for PCR products but also draft and full bacterial genomes as well as assembled metagenomic data sets (http://napdos.ucsd.edu). The sequence tag approach is especially useful for screening complex environmental data such as soil and sediments, where complete gene cluster assemblies are still challenging using recent sequencing technologies, and can be used to infer diversity and genetic potential of natural products in specific environments. ${ }^{\mathbf{1 3 2 , 2 0 2 - 2 0 4}}$ Brady and colleagues developed the webtool esNAPD ${ }^{37}$ and phylogeo, a specialized $\mathrm{R}$ package $\mathrm{e}^{38}$ to facilitate richness and diversity analysis of NRPS and PKS sequence tags in soil and direct the discovery of bioactive natural products from metagenomes as shown for a novel pentangular polyphenol type II polyketide. ${ }^{\mathbf{9 4}}$ This general concept of phylogeny of sequence tags as a guide for secondary metabolite genome mining was also expanded to other enzyme families such as the chromopyrrolic acid synthase responsible for the biosynthesis of rare tryptophan dimers ${ }^{205,206}$ and the epoxyketone family of compounds. ${ }^{132,173}$

A completely new aspect of using phylogeny and evolutionary distances for genome mining purposes has been recently developed by Barona-Gomez and colleagues. ${ }^{33}$ Their EvoMining approach is based on the concept that enzymes involved in secondary metabolism evolved by duplication and subsequent expansion of substrate specificity of primary enzymes and these expanded and repurposed enzyme families are detectable with phylogenetic methods. They developed a genome mining pipeline that detects homologues of certain classes of housekeeping genes and compared the average number and phylogenetic distance of each enzyme family.
As proof of principle two previously uncharacterized enzymes could be identified, an argininosuccinate lyase involved in the biosynthesis of leupeptin and an unusual AroA family enzyme involved in the biosynthesis of a putative novel arseno-organic compound. Both compounds in this case have been linked to known biosynthetic machineries such as NRPS and PKS based systems. However, this approach has not only the potential to detect novel highly unusual and previously uncharacterized enzyme families but could be useful to detect non-canonical secondary metabolic pathways, where no known machinery has been previously described.

\section{Resistance/target based mining methods}

Methods and tools to detect and extract secondary metabolite gene clusters are nowadays quite well established, and with all the microbial genomes available the biggest database at this point, the JGI IMG-ABC database, contains more than 960000 detected gene clusters, ${ }^{46}$ the majority are orphan. Analysing and characterizing each and every one of these orphan gene clusters in real wet-lab experiments is clearly not feasible. The challenge is now to prioritize and focus on the most promising gene clusters and gene cluster families. Which of the gene clusters is most interesting certainly depends on what exactly researchers are looking for and ranges from novel biosynthetic mechanisms, novel structures or derivatives of compounds to new bioactivities and modes of actions. However, predicting bioactivities and mechanisms of actions in silico remains one of the challenges of computational methods in drug discovery.

Resistance based and target based mining techniques are relatively recently developed genome mining approaches that aim to detect secondary metabolite gene clusters based on the self-resistant mechanisms of an antibiotic producing organism. The idea is based on the experience that BGCs not only contain the biochemical enzymes for compound production, but also encode additional important information such as regulatory elements, transporter proteins and resistance mechanisms. A bacterium that produces an antibiotic compound needs to develop self-resistant mechanisms in order to avoid suicide. ${ }^{207}$ The resistant mechanisms vary and include efflux pumps, degrading enzymes to remove toxic compounds, and modified target proteins to prevent binding of antibiotics to the active site of their targets. ${ }^{208}$ The gene clusters responsible for the biosynthesis of the antibiotics novobiocin, ${ }^{209}$ platensin ${ }^{210}$ and griselimycins $^{\mathbf{2 1 1}}$ are some examples were second copies of resistant housekeeping genes $(g y r B, f a b B / F$ and $d n a N$ respectively) are directly encoded within the gene cluster.

The first proof of principle that resistance can be used as a discriminating criterion in antibiotic producing organisms has been published in 2013. Wright and co-authors were able to show that organisms resistant to glycopeptide and ansamycinlike antibiotics are more likely to produce similar chemical compounds, ${ }^{\mathbf{2 1 2}}$ and an antibiotic resistance based discovery platform was developed for the isolation of scaffold-specific antibacterial producers. ${ }^{213}$ Moore and colleagues took this 
approach one step further and developed a target-directed genome mining approach. ${ }^{35}$ By screening 86 highly related strains of the marine actinomycete genus Salinispora for second copies of house keeping genes and relating those to their presence in biosynthetic gene clusters, they were able to identify a duplicated bacterial fatty acid synthase in the direct vicinity of an non-canonical hybrid PKS-NRPS gene cluster. Using direct cloning, heterologous expression and mutational analysis, the gene cluster was linked to the biosynthesis of thiolactomycin, a known fatty acid synthase inhibitor. Thus, correlating putative resistance genes with orphan secondary metabolite gene clusters can be one way to mine bacterial genomes specifically for antibacterial compounds, at least in those cases, where resistance is mediated by target modification.

With the rise of antibiotic resistant pathogens and the urgent need for new antibiotics with novel mode of actions, resistance-based genome mining techniques will be an important toolkit for the discovery of specifically antibacterial compounds and mechanism of action studies in the future. Well-curated databases of resistance genes such as CARD ${ }^{34}$ and $\mathrm{ARDB}^{\mathbf{2 1 4}}$ will play an important part in these efforts. A recent example for an automated online tool that can connect genomic data, chemical structures and resistance genes is PRISM. ${ }^{215}$ Originally created to connect structural information and BGCs in a high throughput fashion, a resistance-determinant library of known antibiotic resistance has been added in order to enable the targeted search for compounds with uncommon modes of action. ${ }^{\mathbf{1 0 4}}$ As proof of principle Johnston and colleagues investigated the telomycin family of natural products and identified a new mode of action for these compounds binding to the phospholipid cardiolipin.

\section{Mining for regulators}

Understanding the complex regulation of secondary metabolites in bacteria has been an important part of in the history of genetics of secondary metabolites. ${ }^{216}$ Especially after whole genome sequences unveiled the large amount of silent gene clusters not active under normal laboratory conditions, researchers are looking for effective ways to activate and optimize production of encoded compounds. Specifically bacteria of the genus Streptomyces have been extensively studied for their complex regulatory networks involved in secondary metabolism. ${ }^{216-218}$ Global and pathway specific regulators, ${ }^{\text {216,218 }}$ precursors from primary metabolism, ${ }^{219}$ and small molecules ${ }^{220,221}$ including $N$-acetylglucosamine ${ }^{222}$ have been shown to play a role in regulation of natural products biosynthesis. Various tools and databases have been developed to predict regulatory elements in bacterial genomes and facilitate drug discovery and compound optimization. ${ }^{223,224}$

One of the best-known systems of globally regulated secondary metabolites present in a wide range of bacteria are metal-chelating agents, including the well known iron binding siderophore compounds. ${ }^{25}$ Siderophores are produced when iron is limited to solubilize and facilitate the uptake of iron into the cells. Other metal chelators are able to bind zinc or copper, respectively. ${ }^{226}$ Involved in production regulation of these metal-chelating compounds are two large families of global regulators, the Fur and the IdeR family of transcriptional repressors. $^{227,228}$ If enough of the respective trace metal is present in the cell, the repressor-metal complex binds upstream of the BGC and silences transcription and production of chelators. If metal concentration in the cytoplasm drops, the metal-regulator complex disintegrates and is no longer able to bind DNA, and production of compounds are activated. Using this knowledge Stegmann and colleagues recently developed a method called INBEKT (Identification of Natural compound Biosynthesis pathways by Exploiting Knowledge of Transcriptional regulation) to mine the genome of Amycolatopsis japonicum MG417-CF17 for the BGC for ethylenediamine-disuccinate (EDDS). ${ }^{36}$ EDDS is a biodegradable zinc-chelating alternative for the widely industrially applied ethylenediamine-tetraacetate (EDTA). No biosynthetic genes could be detected for EDDS using canonical genome mining tools. However, screening the genome of Amycolatopsis japonicum for zinc-binding regions led to the identification and characterization of the aes genes responsible for EDDS production. Considering that certain classes of regulators are more often connected to secondary metabolites than others, this approach could be further developed in the future to mine genomes for non-canonical secondary metabolite pathways.

Consideration of regulators is also an important technique to study fungal secondary metabolite biosynthetic gene clusters.

Many fungal gene clusters encode cluster-specific regulators, which result in activation of the gene cluster when artificially overexpressed. ${ }^{167}$ As the regulator binding sites are often highly conserved, they can be used to identify genes belonging to fungal gene clusters by computational methods, such as implemented in the software CASSIS. ${ }^{229}$ Especially in fungi, genes belonging to the same biosynthetic gene cluster are highly co-regulated. Thus integrating transcriptomics data into the genome mining workflows can provide additional means to identify BGCs and define gene cluster borders. ${ }^{230-232}$ While the first approaches to integrate such data have involved many manual steps, recently easy-to-use web-based implementations of this approach have become available. ${ }^{233}$

\section{Culture independent mining: single cells and metagenomes}

The amount and complexity of metagenomic data makes mining them for secondary metabolites a specifically challenging task. Especially large and highly repetitive gene clusters such as NRPS and PKS pathways are rarely fully assembled. However mining environmental DNA for natural products opens the possibility to explore the large microbial world present that is not yet cultured and study diversity and distribution of these compounds directly in their environment. Heterologous expression and synthetic biology approaches allow subsequent capturing of sequenced pathways and enable compound discovery. ${ }^{\mathbf{9 4 , 2 3 4}}$ During the last decade assembly problems were bypassed by sequence tag approaches and phylogenetic classification to dereplicate and identify 


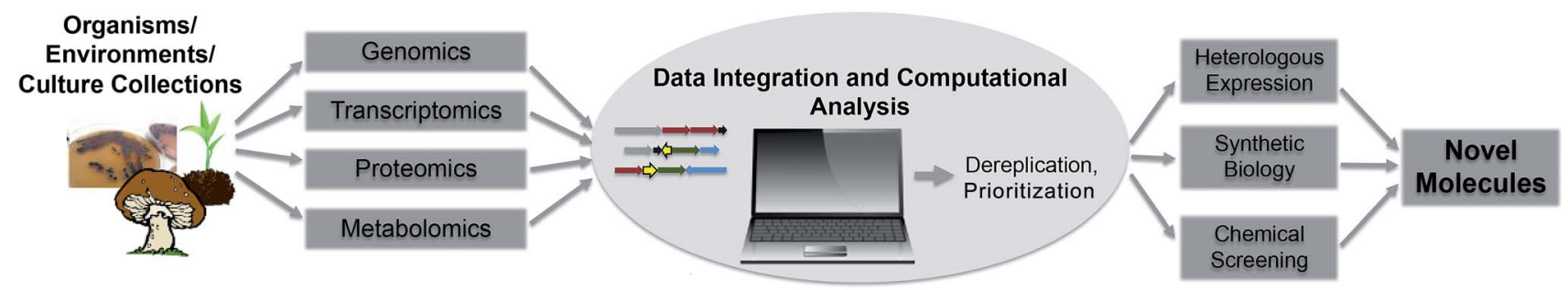

Fig. 3 Flowchart of future automated genome mining approaches.

promising novel biosynthetic gene clusters. Brady and colleagues used sequence tag approaches to discover new compounds directly from soil DNA, ${ }^{94,132,206}$ a diverse environment full of yet uncultured bacterial diversity and hidden natural product potential..$^{51,202,203}$

How much potential the so-called microbial dark matter really contains in terms of chemistry and novel biosynthetic machineries, has been demonstrated by genome mining studies from obligate symbiotic bacteria of ascidians and sponges. ${ }^{140}$ Schmidt and colleagues were able to identify the biosynthetic machinery of the patellamides by screening fosmid libraries from enriched Prochloron DNA, the cyanobacterial symbiont of the ascidian Lissoclinum patella. Heterologous production in $E$. coli proved a highly unusual RiPP pathway was responsible for the biosynthesis of these cyclic peptides (chapter 4). Sequencing the microbiome of further ascidians and bryozoans allowed the assembly of genome sequences of symbiotic proteobacteria, led to the identification of the patellazole and bryostatin gene clusters, and showed the important role of secondary metabolites in these organisms. ${ }^{235-237}$

A combination of metagenomic sequencing and single cell genomics of a sponge microbiome recently revealed a whole new candidate phylum 'Tectomicrobia' widely distributed in sponges. ${ }^{196}$ Two different genomes of the candidate genus 'Entotheonella' were assembled with genomes larger than 9 megabases and multiple biosynthetic gene clusters including the highly unusual polytheonamide pathway. ${ }^{238}$

With sequencing cost constantly falling and improving read length from technologies such as $\mathrm{PacBi}^{239}$ and Nanopore, ${ }^{240}$ assembly and mining of single cells and complex environments will be easier in the future and help to uncover more of the microbial dark matter and the enormous amounts of cryptic gene clusters in unusual environments such as the human microbiome. ${ }^{150}$

\section{Conclusions}

Enabled by the fast development of genome sequencing technologies, genome mining techniques rapidly evolved during the last decade and are currently an important part of drug discovery efforts. Depending on focus and interest of researchers, different mining techniques and approaches have been developed to detect, dereplicate and prioritize secondary metabolite gene clusters. The sheer amount of data available is, and will be challenging in the future, and will drive the constant development of effective computational tools and algorithms to guide wet lab experiments. Sequencing of uncultured organisms and whole environments, hand in hand with the improvements in "omics" technologies, systems biology approaches and synthetic biology will drive automated high-throughput analysis connecting genomic, transcriptomic and metabolomic data to connect genes more efficiently to molecules and vice versa (Fig. 3). Furthermore, the possibilities of studying diversity and distribution of secondary metabolites in their direct environment provides the chance to learn more about the impact of these compounds in their natural habitat. Fascinating examples of complex symbiotic interactions of microbes and their environments regulated by small molecules and secondary metabolites prove their important impact on shaping environmental niches. A true understanding of natural products, their evolution and role in the environment will give important insights in regulation, distribution and mode of action studies and therefore facilitate and maintain their use as human therapeutics.

\section{Acknowledgements}

The authors thank Harald Gross, Evi Stegmann, Yvonne Mast, Bradley Moore, and Michelle Schorn for helpful comments. NZ is funded by the German Center for Infection Biology (DZIF). The work of TW is funded by a grant of the Novo Nordisk Foundation.

\section{References}

1 G. M. Cragg and D. J. Newman, Biochim. Biophys. Acta, Gen. Subj., 2013, 1830, 3670-3695.

2 D. J. Newman and G. M. Cragg, J. Nat. Prod., 2012, 75, 311335.

3 G. L. Challis and D. A. Hopwood, Proc. Natl. Acad. Sci. U. S. A., 2003, 100, 14555-14561.

4 L. F. Wright and D. A. Hopwood, J. Gen. Microbiol., 1976, 96, 289-297.

5 B. A. Rudd and D. A. Hopwood, J. Gen. Microbiol., 1979, 114, 35-43.

6 F. Malpartida and D. A. Hopwood, Nature, 1984, 309, 462464.

7 D. A. Hopwood and H. M. Wright, J. Gen. Microbiol., 1983, 129, 3575-3579.

8 H. Ikeda, H. Kotaki and S. Omura, J. Bacteriol., 1987, 169, 5615-5621.

9 A. Bechthold, J. K. Sohng, T. M. Smith, X. Chu and H. G. Floss, Mol. Gen. Genet., 1995, 248, 610-620. 
10 S. Pelzer, R. Süßmuth, D. Heckmann, J. Recktenwald, P. Huber, G. Jung and W. Wohlleben, Antimicrob. Agents Chemother., 1999, 43, 1565-1573.

11 T. Weber, K. Welzel, S. Pelzer, A. Vente and W. Wohlleben, J. Biotechnol., 2003, 106, 221-232.

12 S. Donadio, M. J. Staver, J. B. McAlpine, S. J. Swanson and L. Katz, Science, 1991, 252, 675-679.

13 S. Bentley, K. Chater, A.-M. Cerdeño-Tárraga, G. L. Challis, N. R. Thomson, K. D. James, D. E. Harris, M. A. Quail, H. Kieser, D. Harper, A. Bateman, S. Brown, G. Chandra, C. W. Chen, M. Collins, A. Cronin, A. Fraser, A. Goble, J. Hidalgo, T. Hornsby, S. Howarth, C.-H. Huang, T. Kieser, L. Larke, L. Murphy, K. Oliver, S. O'Neil, E. Rabbinowitsch, M.-A. Rajandream, K. Rutherford, S. Rutter, K. Seeger, D. Saunders, S. Sharp, R. Squares, S. Squares, K. Taylor, T. Warren, A. Wietzorrek, J. Woodward, B. G. Barrell, J. Parkhill and D. A. Hopwood, Nature, 2002, 417, 141-147.

14 H. Ikeda, J. Ishikawa, A. Hanamoto, M. Shinose, H. Kikuchi, T. Shiba, Y. Sakaki, M. Hattori and S. Omura, Nat. Biotechnol., 2003, 21, 526-531.

15 B. Gust, G. L. Challis, K. Fowler, T. Kieser and K. F. Chater, Proc. Natl. Acad. Sci. U. S. A., 2003, 100, 1541-1546.

16 J. S. Tuan, J. M. Weber, M. J. Staver, J. O. Leung, S. Donadio and L. Katz, Gene, 1990, 90, 21-29.

17 U. J. Kim, H. Shizuya, P. J. de Jong, B. Birren and M. I. Simon, Nucleic Acids Res., 1992, 20, 1083-1085.

18 V. M. Chauthaiwale, A. Therwath and V. V. Deshpande, Microbiol. Rev., 1992, 56, 577-591.

19 C. M. Farnet and E. Zazopoulos, Improving Drug Discovery From Microorganisms in Natural Products: Drug Discovery and Therapeutic Medicine, ed. L. Zhang and A. L. Demain, Humana Press, Totowa, NJ, 2005, pp. 95-106.

20 D. G. Gibson, L. Young, R. Chuang, J. C. Venter, C. a. Hutchison and H. O. Smith, Nat. Methods, 2009, 6, 343-345.

21 K. Yamanaka, K. A. Reynolds, R. D. Kersten, K. S. Ryan, D. J. Gonzalez, V. Nizet, P. C. Dorrestein and B. S. Moore, Proc. Natl. Acad. Sci. U. S. A., 2014, 111, 1957-1962.

22 N. Kouprina and V. Larionov, Nat. Protoc., 2008, 3, 371377.

23 S. H. Sternberg, S. Redding, M. Jinek, E. C. Greene and J. A. Doudna, Nature, 2014, 507, 62-67.

24 Y. Tong, P. Charusanti, L. Zhang, T. Weber and S. Y. Lee, ACS Synth. Biol., 2015, 4, 1020-1029.

25 E. Zazopoulos, K. Huang, A. Staffa, W. Liu, B. O. Bachmann, K. Nonaka, J. Ahlert, J. S. Thorson, B. Shen and C. M. Farnet, Nat. Biotechnol., 2003, 21, 187-190.

26 H. Gross, V. O. Stockwell, M. D. Henkels, B. NowakThompson, J. E. Loper and W. H. Gerwick, Chem. Biol., 2007, 14, 53-63.

27 N. Ziemert, S. Podell, K. Penn, J. H. Badger, E. Allen and P. R. Jensen, PLoS One, 2012, 7, e34064.

28 M. H. Medema, K. Blin, P. Cimermancic, V. de Jager, P. Zakrzewski, M. a. Fischbach, T. Weber, E. Takano and R. Breitling, Nucleic Acids Res., 2011, 39, W339W346.
29 R. D. Kersten, Y.-L. Yang, Y. Xu, P. Cimermancic, S.-J. Nam, W. Fenical, M. A. Fischbach, B. S. Moore and P. C. Dorrestein, Nat. Chem. Biol., 2011, 7, 794-802.

30 R. D. Kersten, N. Ziemert, D. J. Gonzalez, B. M. Duggan, V. Nizet, P. C. Dorrestein and B. S. Moore, Proc. Natl. Acad. Sci. U. S. A., 2013, 110, E4407-E4416.

31 J. Gubbens, H. Zhu, G. Girard, L. Song, B. I. Florea, P. Aston, K. Ichinose, D. V. Filippov, Y. H. Choi, H. S. Overkleeft, G. L. Challis and G. P. Van Wezel, Chem. Biol., 2014, 21, 707-718.

32 K. R. Duncan, M. Crüsemann, A. Lechner, A. Sarkar, J. Li, N. Ziemert, M. Wang, N. Bandeira, B. S. Moore, P. C. Dorrestein and P. R. Jensen, Chem. Biol., 2015, 22, 460-471.

33 P. Cruz-Morales, C. E. Martínez-Guerrero, M. A. MoralesEscalante, L. A. Yáñez-Guerra, J. F. Kopp, J. Feldmann, H. E. Ramos-Aboites and F. Barona-Gomez, bioRxiv, 2015, DOI: 10.1101/020503.

34 A. G. McArthur, N. Waglechner, F. Nizam, A. Yan, M. A. Azad, A. J. Baylay, K. Bhullar, M. J. Canova, G. De Pascale, L. Ejim, L. Kalan, A. M. King, K. Koteva, M. Morar, M. R. Mulvey, J. S. O'Brien, A. C. Pawlowski, L. J. V. Piddock, P. Spanogiannopoulos, A. D. Sutherland, I. Tang, P. L. Taylor, M. Thaker, W. Wang, M. Yan, T. Yu and G. D. Wright, Antimicrob. Agents Chemother., 2013, 57, 3348-3357.

35 X. Tang, J. Li, N. Millán-Aguiñaga, J. J. Zhang, E. C. O'Neill, J. A. Ugalde, P. R. Jensen, S. M. Mantovani and B. S. Moore, ACS Chem. Biol., 2015, 10, 2841-2849.

36 M. Spohn, W. Wohlleben and E. Stegmann, Environ. Microbiol., 2016, 18(4), 1249-1263.

37 B. V. Reddy, A. Milshteyn, Z. Charlop-Powers and S. F. Brady, Chem. Biol., 2014, 21, 1023-1033.

38 Z. Charlop-Powers and S. F. Brady, Bioinformatics, 2015, 13.

39 A. Calteau, D. P. Fewer, A. Latifi, T. Coursin, T. Laurent, J. Jokela, C. a. Kerfeld, K. Sivonen, J. Piel and M. Gugger, BMC Genomics, 2014, 15, 1-14.

40 M. Welker, E. Dittmann and H. Von Döhren, Methods Enzymol., 2012, 517, 23-46.

41 S. C. Wenzel and R. Müller, Comprehensive Natural Products II, 2010.

42 K. Gerth, S. Pradella, O. Perlova, S. Beyer and R. Müller, J. Biotechnol., 2003, 106, 233-253.

43 S. C. Wenzel and R. Müller, Mol. BioSyst., 2009, 5, 567-574. 44 S. Behnken and C. Hertweck, Appl. Microbiol. Biotechnol., 2012, 96, 61-67.

45 A.-C. Letzel, S. J. Pidot and C. Hertweck, Nat. Prod. Rep., 2013, 30, 392-428.

46 M. Hadjithomas, I.-M. A. Chen, K. Chu, A. Ratner, K. Palaniappan, E. Szeto, J. Huang, T. B. K. Reddy, P. Cimermancic, M. A. Fischbach, N. N. Ivanova, V. M. Markowitz, N. C. Kyrpides and A. Pati, MBio, 2015, 6, 1-10.

47 M. H. Medema, R. Kottmann, P. Yilmaz, M. Cummings, J. B. Biggins, K. Blin, I. de Bruijn, Y. H. Chooi, J. Claesen, R. C. Coates, P. Cruz-Morales, S. Duddela, S. Dusterhus, 
D. J. Edwards, D. P. Fewer, N. Garg, C. Geiger, J. P. GomezEscribano, A. Greule, M. Hadjithomas, A. S. Haines, E. J. Helfrich, M. L. Hillwig, K. Ishida, A. C. Jones, C. S. Jones, K. Jungmann, C. Kegler, H. U. Kim, P. Kotter, D. Krug, J. Masschelein, A. V. Melnik, S. M. Mantovani, E. A. Monroe, M. Moore, N. Moss, H. W. Nutzmann, G. Pan, A. Pati, D. Petras, F. J. Reen, F. Rosconi, Z. Rui, Z. Tian, N. J. Tobias, Y. Tsunematsu, P. Wiemann, E. Wyckoff, X. Yan, G. Yim, F. Yu, Y. Xie, B. Aigle, A. K. Apel, C. J. Balibar, E. P. Balskus, F. Barona-Gomez, A. Bechthold, H. B. Bode, R. Borriss, S. F. Brady, A. A. Brakhage, P. Caffrey, Y. Q. Cheng, J. Clardy, R. J. Cox, R. De Mot, S. Donadio, M. S. Donia, W. A. van der Donk, P. C. Dorrestein, S. Doyle, A. J. Driessen, M. Ehling-Schulz, K. D. Entian, M. A. Fischbach, L. Gerwick, W. H. Gerwick, H. Gross, B. Gust, C. Hertweck, M. Hofte, S. E. Jensen, J. Ju, L. Katz, L. Kaysser, J. L. Klassen, N. P. Keller, J. Kormanec, O. P. Kuipers, T. Kuzuyama, N. C. Kyrpides, H. J. Kwon, S. Lautru, R. Lavigne, C. Y. Lee, B. Linquan, X. Liu, W. Liu, A. Luzhetskyy, T. Mahmud, Y. Mast, C. Mendez, M. Metsa-Ketela, J. Micklefield, D. A. Mitchell, B. S. Moore, L. M. Moreira, R. Muller, B. A. Neilan, M. Nett, J. Nielsen, F. O'Gara, H. Oikawa, A. Osbourn, M. S. Osburne, B. Ostash, S. M. Payne, J. L. Pernodet, M. Petricek, J. Piel, O. Ploux, J. M. Raaijmakers, J. A. Salas, E. K. Schmitt, B. Scott, R. F. Seipke, B. Shen, D. H. Sherman, K. Sivonen, M. J. Smanski, M. Sosio, E. Stegmann, R. D. Süssmuth, K. Tahlan, C. M. Thomas, Y. Tang, A. W. Truman, M. Viaud, J. D. Walton, C. T. Walsh, T. Weber, G. P. van Wezel, B. Wilkinson, J. M. Willey, W. Wohlleben, G. D. Wright, N. Ziemert, C. Zhang, S. B. Zotchev, R. Breitling, E. Takano and F. O. Glöckner, Nat. Chem. Biol., 2015, 11, 625-631.

48 S. F. Altschul, W. Gish, W. Miller, E. W. Myers and D. J. Lipman, J. Mol. Biol., 1990, 215, 403-410.

49 B. Buchfink, C. Xie and D. H. Huson, Nat. Methods, 2015, 12, 59-60.

50 R. D. Finn, J. Clements and S. R. Eddy, Nucleic Acids Res., 2011, 39, DOI: 10.1093/nar/gkr367.

51 L. L. Ling, T. Schneider, A. J. Peoples, A. L. Spoering, I. Engels, B. P. Conlon, A. Mueller, T. F. Schaberle, D. E. Hughes, S. Epstein, M. Jones, L. Lazarides, V. A. Steadman, D. R. Cohen, C. R. Felix, K. A. Fetterman, W. P. Millett, A. G. Nitti, A. M. Zullo, C. Chen, K. Lewis, T. F. Schaberle, D. E. Hughes, S. Epstein, M. Jones, L. Lazarides, V. A. Steadman, D. R. Cohen, C. R. Felix, K. A. Fetterman, W. P. Millett, A. G. Nitti, A. M. Zullo, C. Chen and K. Lewis, Nature, 2015, 517, 455-459.

52 J. Claesen and M. Bibb, Proc. Natl. Acad. Sci. U. S. A., 2010, 107, 16297-16302.

53 L. C. Foulston and M. J. Bibb, Proc. Natl. Acad. Sci. U. S. A., 2010, 107, 13461-13466.

54 M. Spohn, N. Kirchner, A. Kulik, A. Jochim, F. Wolf, P. Muenzer, O. Borst, H. Gross, W. Wohlleben and E. Stegmann, Antimicrob. Agents Chemother., 2014, 58, 6185-6196.
55 N. Ziemert, K. Ishida, P. Quillardet, C. Bouchier, C. Hertweck, N. T. de Marsac and E. Dittmann, Appl. o, 2008, 74, 1791-1797.

56 N. Ziemert, K. Ishida, A. Liaimer, C. Hertweck and E. Dittmann, Angew. Chem., Int. Ed. Engl., 2008, 47, 77567759.

57 Z. Xu, Z. Sun, S. Li, Z. Xu, C. Cao, Z. Xu, X. Feng and H. Xu, Sci. Rep., 2015, 5, 17400.

58 A. de Jong, S. a F. T. van Hijum, J. J. E. Bijlsma, J. Kok and O. P. Kuipers, Nucleic Acids Res., 2006, 34, 273-279.

59 T. Weber, C. Rausch, P. Lopez, I. Hoof, V. Gaykova, D. H. Huson and W. Wohlleben, J. Biotechnol., 2009, 140, 13-17.

60 T. Weber and H. U. Kim, Synthetic and Systems Biotechnology, 2016, 1, 69-79, DOI: 10.1016/ j.synbio.2015.12.002.

61 B. O. Bachmann, S. G. Van Lanen and R. H. Baltz, J. Ind. Microbiol. Biotechnol., 2014, 41, 175-184.

62 C. N. Boddy, J. Ind. Microbiol. Biotechnol., 2014, 41, 443-450.

63 E. J. N. Helfrich, S. Reiter and J. Piel, Curr. Opin. Biotechnol., 2014, 29, 107-115.

64 M. H. Medema and M. A. Fischbach, Nat. Chem. Biol., 2015, 11, 639-648.

65 M. Nett, Prog. Chem. Org. Nat. Prod., 2014, 99, 199-245.

66 R. J. Scheffler, S. Colmer, H. Tynan, A. L. Demain and V. P. Gullo, Appl. Microbiol. Biotechnol., 2013, 97, 969-978.

67 J. I. Tietz and D. A. Mitchell, Curr. Top. Med. Chem., 2015, 16, 1645-1694.

68 T. Weber, Int. J. Med. Microbiol., 2014, 304, 230-235.

69 J. Yaegashi, B. R. Oakley and C. C. Wang, J. Ind. Microbiol. Biotechnol., 2014, 41, 433-442.

70 M. H. Li, P. M. Ung, J. Zajkowski, S. Garneau-Tsodikova and D. H. Sherman, BMC Bioinf., 2009, 10, 185.

71 C. Rausch, T. Weber, O. Kohlbacher, W. Wohlleben and D. H. Huson, Nucleic Acids Res., 2005, 33, 5799-5808.

72 M. Röttig, M. H. Medema, K. Blin, T. Weber, C. Rausch and O. Kohlbacher, Nucleic Acids Res., 2011, 39, W362W367.

73 M. A. Skinnider, C. W. Johnston, R. Zvanych and N. A. Magarvey, ChemBioChem, 2015, 16, 223-227.

74 A. Starcevic, J. Zucko, J. Simunkovic, P. F. Long, J. Cullum and D. Hranueli, Nucleic Acids Res., 2008, 36, 6882-6892.

75 A. de Jong, A. J. van Heel, J. Kok and O. P. Kuipers, Nucleic Acids Res., 2010, 38, W647-W651.

76 A. J. van Heel, A. de Jong, M. Montalban-Lopez, J. Kok, O. P. Kuipers, M. Montalbán-López, J. Kok and O. P. Kuipers, Nucleic Acids Res., 2013, 41, W448-W453.

77 K. Blin, M. H. Medema, D. Kazempour, M. A. Fischbach, R. Breitling, E. Takano and T. Weber, Nucleic Acids Res., 2013, 41, W204-W212.

78 T. Weber, K. Blin, S. Duddela, D. Krug, H. U. Kim, R. Bruccoleri, S. Y. Lee, M. a. Fischbach, R. Müller, W. Wohlleben, R. Breitling, E. Takano and M. H. Medema, Nucleic Acids Res., 2015, 43, W237-W243.

79 B. Shen, Hindra, X. Yan, T. Huang, H. Ge, D. Yang, Q. Teng, J. D. Rudolf and J. R. Lohman, Bioorg. Med. Chem. Lett., 2015, 25, 9-15. 
80 J. B. McAlpine, B. O. Bachmann, M. Piraee, S. Tremblay, A. M. Alarco, E. Zazopoulos and C. M. Farnet, J. Nat. Prod., 2005, 68, 493-496.

81 M. Juguet, S. Lautru, F. X. Francou, S. Nezbedova, P. Leblond, M. Gondry and J. L. Pernodet, Chem. Biol., 2009, 16, 421-431.

82 F. Karray, E. Darbon, N. Oestreicher, H. Dominguez, K. Tuphile, J. Gagnat, M. H. Blondelet-Rouault, C. Gerbaud and J. L. Pernodet, Microbiology, 2007, 153, 4111-4122.

83 L. Laureti, L. Song, S. Huang, C. Corre, P. Leblond, G. L. Challis and B. Aigle, Proc. Natl. Acad. Sci. U. S. A., 2011, 108, 6258-6263.

84 G. Yadav, R. S. Gokhale and D. Mohanty, Nucleic Acids Res., 2003, 31, 3654-3658.

85 D. W. Udwary, L. Zeigler, R. N. Asolkar, V. Singan, A. Lapidus, W. Fenical, P. R. Jensen and B. S. Moore, Proc. Natl. Acad. Sci. U. S. A., 2007, 104, 10376-10381.

86 C. J. Schulze, M. S. Donia, J. L. Siqueira-Neto, D. Ray, J. A. Raskatov, R. E. Green, J. H. McKerrow, M. A. Fischbach and R. G. Linington, ACS Chem. Biol., 2015, 10, 2373-2381.

87 J. Piel, Proc. Natl. Acad. Sci. U. S. A., 2002, 99, 14002-14007. 88 E. J. N. Helfrich and J. Piel, Nat. Prod. Rep., 2016, 33, 231316.

89 R. V. O'Brien, R. W. Davis, C. Khosla and M. E. Hillenmeyer, J. Antibiot., 2014, 67, 89-97.

90 T. Nguyen, K. Ishida, H. Jenke-Kodama, E. Dittmann, C. Gurgui, T. Hochmuth, S. Taudien, M. Platzer, C. Hertweck and J. Piel, Nat. Biotechnol., 2008, 26, 225-233.

91 D. Pistorius and R. Müller, ChemBioChem, 2012, 13, 416426.

92 R. Ueoka, A. R. Uria, S. Reiter, T. Mori, P. Karbaum, E. E. Peters, E. J. N. Helfrich, B. I. Morinaka, M. Gugger, H. Takeyama, S. Matsunaga and J. Piel, Nat. Chem. Biol., 2015, 11, 705-712.

93 J. Tian, H. Chen, Z. Guo, N. Liu, J. Li, Y. Huang, W. Xiang and Y. Chen, Appl. Microbiol. Biotechnol., 2016, 100, 41894199.

94 H. Kang and S. F. Brady, J. Am. Chem. Soc., 2014, 136, 1811118119.

95 M. Knudsen, D. Sondergaard, C. Tofting-Olesen, F. T. Hansen, D. E. Brodersen and C. N. Pedersen, Bioinformatics, 2016, 32, 325-329.

96 B. O. Bachmann and J. Ravel, Methods Enzymol., 2009, 458, 181-217.

97 D. Baranašić, J. Zucko, J. Diminic, R. Gacesa, P. F. Long, J. Cullum, D. Hranueli and A. Starcevic, J. Ind. Microbiol. Biotechnol., 2014, 41, 461-467.

98 C. Prieto, C. Garcia-Estrada, D. Lorenzana and J. F. Martin, Bioinformatics, 2012, 28, 426-427.

99 B. S. E. Editor and J. M. Walker, 1401.

100 D. D. Nguyen, C.-H. H. Wu, W. J. Moree, A. Lamsa, M. H. Medema, X. Zhao, R. G. Gavilan, M. Aparicio, L. Atencio, C. Jackson, J. Ballesteros, J. Sanchez, J. D. Watrous, V. V. Phelan, C. van de Wiel, R. D. Kersten, S. Mehnaz, R. De Mot, E. a. Shank, P. Charusanti,
H. Nagarajan, B. M. Duggan, B. S. Moore, N. Bandeira, B. Ø. O. Palsson, K. Pogliano, M. Gutiérrez and P. C. Dorrestein, Proc. Natl. Acad. Sci. U. S. A., 2013, 110, E2611-E2620.

101 A. Ibrahim, L. Yang, C. Johnston, X. Liu, B. Ma and N. A. Magarvey, Proc. Natl. Acad. Sci. U. S. A., 2012, 109, 19196-19201.

102 H. Mohimani, W. T. Liu, R. D. Kersten, B. S. Moore, P. C. Dorrestein and P. A. Pevzner, J. Nat. Prod., 2014, 77, 1902-1909.

103 M. H. Medema, Y. Paalvast, D. D. Nguyen, A. Melnik, P. C. Dorrestein, E. Takano and R. Breitling, PLoS Comput. Biol., 2014, 10, e1003822.

104 C. W. Johnston, M. A. Skinnider, C. A. Dejong, P. N. Rees, G. M. Chen, C. G. Walker, S. French, E. D. Brown, J. Bérdy, D. Y. Liu and N. A. Magarvey, Nat. Chem. Biol., 2016, DOI: 10.1038/nchembio.2018.

105 M. A. Wyatt, W. Wang, C. M. Roux, F. C. Beasley, D. E. Heinrichs, P. M. Dunman and N. A. Magarvey, Science, 2010, 329(80), 294-296.

106 S. Lautru, R. J. Deeth, L. M. Bailey and G. L. Challis, Nat. Chem. Biol., 2005, 1, 265-269.

107 H. Wang, D. P. Fewer, L. Holm, L. Rouhiainen and K. Sivonen, Proc. Natl. Acad. Sci. U. S. A., 2014, 111, 92599264.

108 M. Begley, P. D. Cotter, C. Hill and R. P. Ross, Appl. Environ. Microbiol., 2009, 75, 5451-5460.

109 Y. Goto, B. Li, J. Claesen, Y. Shi, M. J. Bibb and W. A. van der Donk, PLoS Biol., 2010, 8, e1000339.

110 L. S. Family, Y. Goto, A. Okesli and W. A. van der Donk, Biochemistry, 2011, 50, 891-898.

111 J. R. Doroghazi and W. W. Metcalf, BMC Genomics, 2013, 14, 611-623.

112 C. L. Cox, J. R. Doroghazi and D. A. Mitchell, BMC Genomics, 2015, 16, 778.

113 D. Iftime, A. Kulik, T. Härtner, S. Rohrer, T. H. Niedermeyer, E. Stegmann, T. Weber and W. Wohlleben, J. Ind. Microbiol. Biotechnol., 2015, 43, 277-291.

114 D. Iftime, M. Jasyk, A. Kulik, J. F. Imhoff, E. Stegmann, W. Wohlleben, R. D. Süssmuth and T. Weber, ChemBioChem, 2015, 16, 2615-2623.

115 J. P. Gomez-Escribano and M. J. Bibb, Methods Enzymol., 2012, 517, 279-300.

116 H. Mohimani, R. D. Kersten, W. T. Liu, M. Wang, S. O. Purvine, S. Wu, H. M. Brewer, L. Pasa-Tolic, N. Bandeira, B. S. Moore, P. A. Pevzner and P. C. Dorrestein, ACS Chem. Biol., 2014, 9, 1545-1551.

117 J. D. Hegemann, M. Zimmermann, X. Xie and M. A. Marahiel, Acc. Chem. Res., 2015, 48, 1909-1919.

118 S. Duquesne, D. Destoumieux-Garzon, S. Zirah, C. Goulard, J. Peduzzi and S. Rebuffat, Chem. Biol., 2007, 14, 793-803.

119 J. O. Solbiati, M. Ciaccio, R. N. Farias, J. E. Gonzalez-Pastor, F. Moreno and R. A. Salomon, J. Bacteriol., 1999, 181, 26592662.

120 J. O. Solbiati, M. Ciaccio, R. N. Farias and R. A. Salomon, J. Bacteriol., 1996, 178, 3661-3663. 
121 T. A. Knappe, U. Linne, S. Zirah, S. Rebuffat, X. Xie and M. A. Marahiel, J Am. Chem. Soc., 2008, 130, 11446-11454. 122 D. W. Christianson, Curr. Opin. Chem. Biol., 2008, 12, 141-150. 123 C. Nakano, H. K. Kim and Y. Ohnishi, ChemBioChem, 2011, 12, 1988-1991.

124 A. Meguro, T. Tomita, M. Nishiyama and T. Kuzuyama, ChemBioChem, 2013, 14, 316-321.

125 Y. Matsuda, T. Mitsuhashi, Z. Quan and I. Abe, Org. Lett., 2015, 17, 4644-4647.

126 Y. Yamada, S. Arima, T. Nagamitsu, K. Johmoto, H. Uekusa, T. Eguchi, K. Shin-ya, D. E. Cane and H. Ikeda, J. Antibiot., 2015, 68, 385-394.

127 Y. Yamada, T. Kuzuyama, M. Komatsu, K. Shin-Ya, S. Omura, D. E. Cane and H. Ikeda, Proc. Natl. Acad. Sci. U. S. A., 2015, 112, 857-862.

128 I. Takeda, M. Umemura, H. Koike, K. Asai and M. Machida, DNA Res., 2014, 1-11.

129 A. Hornung, M. Bertazzo, A. Dziarnowski, K. Schneider, K. Welzel, S. E. Wohlert, M. Holzenkampfer, G. J. Nicholson, A. Bechthold, R. D. Süßmuth, A. Vente and S. Pelzer, ChemBioChem, 2007, 8, 757-766.

130 C. Ross, K. Scherlach, F. Kloss and C. Hertweck, Angew. Chem., Int. Ed. Engl., 2014, 53, 7794-7798.

131 X. Zhu, M. Su, K. Manickam and W. Zhang, ACS Chem. Biol., 2015, 10, 2785-2793.

132 J. G. Owen, Z. Charlop-Powers, A. G. Smith, M. a. Ternei, P. Y. Calle, B. V. B. Reddy, D. Montiel and S. F. Brady, Proc. Natl. Acad. Sci. U. S. A., 2015, 112, 201501124.

133 T. Weber, P. Charusanti, E. M. Musiol-Kroll, X. Jiang, Y. Tong, H. U. Kim and S. Y. Lee, Trends Biotechnol., 2015, 33, 15-26.

134 M. H. Medema, E. Takano and R. Breitling, Mol. Biol. Evol., 2013, 30, 1218-1223.

135 S. Zhao, A. Sakai, X. Zhang, M. W. Vetting, R. Kumar, B. Hillerich, B. San Francisco, J. Solbiati, A. Steves, S. Brown, E. Akiva, A. Barber, R. D. Seidel, P. C. Babbitt, S. C. Almo, J. A. Gerlt and M. P. Jacobson, eLife, 2014, 3:e03275.

136 H. J. Atkinson, J. H. Morris, T. E. Ferrin and P. C. Babbitt, PLoS One, 2009, 4, e4345.

137 J. D. Rudolf, X. Yan and B. Shen, J. Ind. Microbiol. Biotechnol., 2016, 43, 261-276.

138 Y. In, M. Doi, M. Inoue, T. Ishida, Y. Hamada and T. Shioiri, Acta Crystallogr., Sect. C: Cryst. Struct. Commun., 1994, 50, 432-434.

139 E. W. Schmidt, S. Sudek and M. G. Haygood, J. Nat. Prod., 2004, 67, 1341-1345.

140 E. W. Schmidt, J. T. Nelson, D. A. Rasko, S. Sudek, J. A. Eisen, M. G. Haygood and J. Ravel, Proc. Natl. Acad. Sci. U. S. A., 2005, 102, 7315-7320.

141 M. S. Donia and E. W. Schmidt, Chem. Biol., 2011, 18, 508519.

142 N. Leikoski, D. P. Fewer and K. Sivonen, Appl. Environ. Microbiol., 2009, 75, 853-857.

143 M. S. Donia, B. J. Hathaway, S. Sudek, M. G. Haygood, M. J. Rosovitz, J. Ravel and E. W. Schmidt, Nat. Chem. Biol., 2006, 2, 729-735.
144 B. Philmus, G. Christiansen, W. Y. Yoshida and T. K. Hemscheidt, ChemBioChem, 2008, 9, 3066-3073.

145 A. R. Weiz, K. Ishida, K. Makower, N. Ziemert, C. Hertweck and E. Dittmann, Chem. Biol., 2011, 18, 1413-1421.

146 N. Ziemert, K. Ishida, A. Weiz, C. Hertweck and E. Dittmann, Appl. Environ. Microbiol., 2010, 76, 3568-3574.

147 M. L. Micallef, P. M. D'Agostino, D. Sharma, R. Viswanathan and M. C. Moffitt, BMC Genomics, 2015, 16, 669.

148 I. Takeda, M. Umemura, H. Koike, K. Asai and M. Machida, DNA Res., 2014, 1-11.

149 P. Cimermancic, M. H. Medema, J. Claesen, K. Kurita, L. C. Wieland Brown, K. Mavrommatis, A. Pati, P. A. Godfrey, M. Koehrsen, J. Clardy, B. W. Birren, E. Takano, A. Sali, R. G. Linington and M. A. Fischbach, Cell, 2014, 158, 412-421.

150 M. S. Donia, P. Cimermancic, C. J. Schulze, L. C. Wieland Brown, J. Martin, M. Mitreva, J. Clardy, R. G. Linington and M. A. Fischbach, Cell, 2014, 158, 1402-1414.

151 M. S. Donia and M. A. Fischbach, Science, 2015, 349(80), 1254766.

152 J. R. Doroghazi, J. C. Albright, A. W. Goering, K.-S. S. Ju, R. R. Haines, K. a. Tchalukov, D. P. Labeda, N. L. Kelleher and W. W. Metcalf, Nat. Chem. Biol., 2014, 10, 963-968.

153 C. R. Goodwin, B. C. Covington, D. K. Derewacz, C. R. McNees, J. P. Wikswo, J. A. McLean and B. O. Bachmann, Chem. Biol., 2015, 22, 661-670.

154 M. Maansson, N. G. Vynne, A. Klitgaard, J. L. Nybo, J. Melchiorsen, D. D. Nguyen, L. M. Sanchez, N. Ziemert, P. C. Dorrestein, M. R. Andersen and L. Gram, mSystems, 2016, 1, e00028-15.

155 K. Kleigrewe, J. Almaliti, I. Y. Tian, R. B. Kinnel, A. Korobeynikov, E. A. Monroe, B. M. Duggan, V. Di Marzo, D. H. Sherman, P. C. Dorrestein, L. Gerwick and W. H. Gerwick, J. Nat. Prod., 2015, 78, 1671-1682.

156 M. Bastian, S. Heymann and M. Jacomy, Third Int. AAAI Conf. Weblogs Soc. Media, 2009, pp. 361-362.

157 Y. Hu, Math. J., 2005, 10, 37-71.

158 Y. M. Chiang, E. Szewczyk, A. D. Davidson, N. Keller, B. R. Oakley and C. C. Wang, J. Am. Chem. Soc., 2009, 131, 2965-2970.

159 L. Song, F. Barona-Gomez, C. Corre, L. Xiang, D. W. Udwary, M. B. Austin, J. P. Noel, B. S. Moore and G. L. Challis, J. Am. Chem. Soc., 2006, 128, 14754-14755.

160 C. Zachow, G. Jahanshah, I. de Bruijn, C. Song, F. Ianni, Z. Pataj, H. Gerhardt, I. Pianet, M. Lammerhofer, G. Berg, H. Gross and J. M. Raaijmakers, Mol. Plant-Microbe Interact., 2015, 28, 800-810.

161 I. de Bruijn, M. J. de Kock, M. Yang, P. de Waard, T. A. van Beek and J. M. Raaijmakers, Mol. Microbiol., 2007, 63, 417428.

162 M. Z. Ansari, G. Yadav, R. S. Gokhale and D. Mohanty, Nucleic Acids Res., 2004, 32, 405-413.

163 H. M. Park, B. G. Kim, D. Chang, S. Malla, H. S. Joo, E. J. Kim, S. J. Park, J. K. Sohng and P. I. Kim, Appl. Microbiol. Biotechnol., 2013, 97, 1213-1222. 
164 M. van der Voort, H. J. Meijer, Y. Schmidt, J. Watrous, E. Dekkers, R. Mendes, P. C. Dorrestein, H. Gross and J. M. Raaijmakers, Front. Microbiol., 2015, 6, 693.

165 N. Khaldi, F. T. Seifuddin, G. Turner, D. Haft, W. C. Nierman, K. H. Wolfe and N. D. Fedorova, Fungal Genet. Biol., 2010, 47, 736-741.

166 M. Gressler, C. Zaehle, K. Scherlach, C. Hertweck and M. Brock, Chem. Biol., 2011, 18, 198-209.

167 S. Bergmann, J. Schumann, K. Scherlach, C. Lange, A. A. Brakhage and C. Hertweck, Nat. Chem. Biol., 2007, 3, 213-217.

168 T. Awakawa, X. L. Yang, T. Wakimoto and I. Abe, ChemBioChem, 2013, 14, 2095-2099.

169 Y. Sun, T. Tomura, J. Sato, T. Iizuka, R. Fudou and M. Ojika, Molecules, 2016, 21, 59.

170 X. L. Yang, T. Awakawa, T. Wakimoto and I. Abe, ChemBioChem, 2014, 15, 1578-1583.

171 C. Wu, R. Cichewicz, Y. Li, J. Liu, B. Roe, J. Ferretti, J. Merritt and F. Qi, Appl. Environ. Microbiol., 2010, 76, 5815-5826.

172 P. M. Joyner, J. Liu, Z. Zhang, J. Merritt, F. Qi and R. H. Cichewicz, Org. Biomol. Chem., 2010, 8, 5486-5489.

173 M. Schorn, J. Zettler, J. P. Noel, P. C. Dorrestein, B. S. Moore and L. Kaysser, ACS Chem. Biol., 2014, 9, 301-309.

$174 \mathrm{~J}$. D. Hegemann, M. Zimmermann, X. Xie and M. A. Marahiel, J. Am. Chem. Soc., 2013, 135, 210-222.

175 T. L. Bailey and C. Elkan, Proc. Int. Conf. Intell. Syst. Mol. Biol., 5th, 1995, 3, 21-29.

176 T. L. Bailey and M. Gribskov, J. Comput. Biol., 1998, 5, 211221.

177 M. O. Maksimov, I. Pelczer and A. J. Link, Proc. Natl. Acad. Sci. U. S. A., 2012, 109, 15223-15228.

178 J. D. Hegemann, M. Zimmermann, S. Zhu, D. Klug and M. A. Marahiel, Biopolymers, 2013, 100, 527-542.

179 J. D. Hegemann, M. Zimmermann, S. Zhu, H. Steuber, K. Harms, X. Xie and M. A. Marahiel, Angew. Chem., Int. Ed. Engl., 2014, 53, 2230-2234.

180 S. S. Elsayed, F. Trusch, H. Deng, A. Raab, I. Prokes, K. Busarakam, J. A. Asenjo, B. A. Andrews, P. van West, A. T. Bull, M. Goodfellow, Y. Yi, R. Ebel, M. Jaspars and M. E. Rateb, J. Org. Chem., 2015, 80, 10252-10260.

181 N. Leikoski, L. Liu, J. Jokela, M. Wahlsten, M. Gugger, A. Calteau, P. Permi, C. A. Kerfeld, K. Sivonen and D. P. Fewer, Chem. Biol., 2013, 20, 1033-1043.

182 C. Nakano, M. Oshima, N. Kurashima and T. Hoshino, ChemBioChem, 2015, 16, 772-781.

183 Y. Matsuda, T. Mitsuhashi, Z. Quan and I. Abe, Org. Lett., 2015, 17, 4644-4647.

184 F. J. Ayala, J. Hered., 1975, 68, 3-10.

185 M. A. Fischbach, C. T. Walsh and J. Clardy, Proc. Natl. Acad. Sci. U. S. A., 2008, 105, 4601-4608.

186 M. C. Moffitt and B. a. Neilan, J. Mol. Evol., 2003, 56, 446457.

187 H. Jenke-Kodama, T. Börner and E. Dittmann, PLoS Comput. Biol., 2006, 2, 1210-1218.

188 H. Jenke-Kodama and E. Dittmann, Phytochemistry, 2009, 70, 1858-1866.
189 J. Zucko, P. F. Long, D. Hranueli and J. Cullum, J. Ind. Microbiol. Biotechnol., 2012, 39, 1541-1547.

190 M. H. Medema, P. Cimermancic, A. Sali, E. Takano and M. A. Fischbach, PLoS Comput. Biol., 2014, 10, e1004016.

191 I. Schmitt and F. K. Barker, Nat. Prod. Rep., 2009, 26, 15851602.

192 N. Ziemert and P. R. Jensen, in Methods in Enzymology, Elsevier Inc., 2012, vol. 517, pp. 161-182.

193 U. R. Abdelmohsen, C. Yang, H. Horn, D. Hajjar, T. Ravasi and U. Hentschel, Mar. Drugs, 2014, 12, 2771-2789.

194 N. Ziemert, A. Lechner, M. Wietz, N. Millán-Aguiñaga, K. L. Chavarria and P. R. Jensen, Proc. Natl. Acad. Sci. U. S. A., 2014, 111, E1130-E1139.

195 J. R. Doroghazi and D. H. Buckley, BMC Genomics, 2014, 15, 970.

196 M. C. Wilson, T. Mori, C. Rückert, A. R. Uria, M. J. Helf, K. Takada, C. Gernert, U. a E. Steffens, N. Heycke, S. Schmitt, C. Rinke, E. J. N. Helfrich, A. O. Brachmann, C. Gurgui, T. Wakimoto, M. Kracht, M. Crüsemann, U. Hentschel, I. Abe, S. Matsunaga, J. Kalinowski, H. Takeyama and J. Piel, Nature, 2014, 506, 58-62.

197 P. Liras, A. Rodríguez-García and J. F. Martín, Int. Microbiol., 1998, 1, 271-278.

198 J. A. Eisen and M. Wu, Theor. Popul. Biol., 2002, 61, 481-487.

199 J. A. Eisen and C. M. Fraser, Science, 2003, 300(80), 17061707.

200 M. Metsä-Ketelä, L. Halo, E. Munukka, J. Hakala, P. Mäntsäla and K. Ylihonko, Appl. Environ. Microbiol., 2002, 68, 4472-4479.

201 E. a. Gontang, S. P. Gaudêncio, W. Fenical and P. R. Jensen, Appl. Environ. Microbiol., 2010, 76, 2487-2499.

202 H. Morlon, T. K. O'Connor, J. a. Bryant, L. K. Charkoudian, K. M. Docherty, E. Jones, S. W. Kembel, J. L. Green and B. J. M. Bohannan, PLoS One, 2015, 10, e0130659.

203 Z. Charlop-Powers, J. G. Owen, B. V. B. Reddy, M. a. Ternei and S. F. Brady, Proc. Natl. Acad. Sci. U. S. A., 2014, 111, 3757-3762.

204 J. N. Woodhouse, L. Fan, M. V. Brown, T. Thomas and B. A. Neilan, ISME J., 2013, 7, 1842-1851.

205 F. Y. Chang, M. A. Ternei, P. Y. Calle and S. F. Brady, J. Am. Chem. Soc., 2013, 135, 17906-17912.

206 F.-Y. Chang, M. A. Ternei, P. Y. Calle and S. F. Brady, J. Am. Chem. Soc., 2015, 137, 6044-6052.

207 V. M. D'Costa, C. E. King, L. Kalan, M. Morar, W. W. L. Sung, C. Schwarz, D. Froese, G. Zazula, F. Calmels, R. Debruyne, G. B. Golding, H. N. Poinar and G. D. Wright, Nature, 2011, 477, 457-461.

208 G. Cox and G. D. Wright, Int. J. Med. Microbiol., 2013, 303, 287-292.

209 M. Steffensky, A. Mühlenweg, Z. X. Wang, S. M. Li and L. Heide, Antimicrob. Agents Chemother., 2000, 44, 12141222.

210 R. M. Peterson, T. Huang, J. D. Rudolf, M. J. Smanski and B. Shen, Chem. Biol., 2014, 21, 389-397.

211 A. Kling, P. Lukat, D. V. Almeida, A. Bauer, E. Fontaine, S. Sordello, N. Zaburannyi, J. Herrmann, S. C. Wenzel, C. Konig, N. C. Ammerman, M. B. Barrio, K. Borchers, 
F. Bordon-Pallier, M. Bronstrup, G. Courtemanche, M. Gerlitz, M. Geslin, P. Hammann, D. W. Heinz, H. Hoffmann, S. Klieber, M. Kohlmann, M. Kurz, C. Lair, H. Matter, E. Nuermberger, S. Tyagi, L. Fraisse, J. H. Grosset, S. Lagrange and R. Muller, Science, 2015, 348(80), 1106-1112.

212 M. N. Thaker, W. Wang, P. Spanogiannopoulos, N. Waglechner, A. M. King, R. Medina and G. D. Wright, Nat. Biotechnol., 2013, 31, 922-927.

213 M. N. Thaker, N. Waglechner and G. D. Wright, Nat. Protoc., 2014, 9, 1469-1479.

214 B. Liu and M. Pop, Nucleic Acids Res., 2009, 37, D443-D447. 215 M. A. Skinnider, C. A. Dejong, P. N. Rees, C. W. Johnston, H. Li, A. L. H. L. H. Webster, M. A. Wyatt and N. A. Magarvey, Nucleic Acids Res., 2015, 43, 9645-9662.

216 G. P. van Wezel and K. J. McDowall, Nat. Prod. Rep., 2011, 28, 1311-1333.

217 M. J. Bibb, Curr. Opin. Microbiol., 2005, 8, 208-215.

218 G. Liu, K. F. Chater, G. Chandra, G. Niu and H. Tan, Microbiol. Mol. Biol. Rev., 2013, 77, 112-143.

219 J. Thykaer, J. Nielsen, W. Wohlleben, T. Weber, M. Gutknecht, A. E. Lantz and E. Stegmann, Metab. Eng., 2010, 12, 455-461.

220 C. Corre, L. Song, S. O'Rourke, K. F. Chater and G. L. Challis, Proc. Natl. Acad. Sci. U. S. A., 2008, 105, 17510-17515.

221 J. H. Shin, A. K. Singh, D. J. Cheon and J. H. Roe, J. Bacteriol., 2011, 193, 75-81.

222 M. Craig, S. Lambert, S. Jourdan, E. Tenconi, S. Colson, M. Maciejewska, M. Ongena, J. F. Martin, G. van Wezel and S. Rigali, Environ. Microbiol. Rep., 2012, 4, 512-521.

223 E. Michta, K. Schad, K. Blin, R. Ort-Winklbauer, M. Röttig, O. Kohlbacher, W. Wohlleben, E. Schinko and Y. Mast, Environ. Microbiol., 2012, 14, 3203-3219.

224 S. Hiard, R. Marée, S. Colson, P. A. Hoskisson, F. Titgemeyer, G. P. van Wezel, B. Joris, L. Wehenkel and S. Rigali, Biochem. Biophys. Res. Commun., 2007, 357, 861-864.

225 R. Saha, N. Saha, R. S. Donofrio and L. L. Bestervelt, J. Basic Microbiol., 2013, 53, 303-317.
226 E. Ahmed and S. J. M. Holmström, Microb. Biotechnol., 2014, 7, 196-208.

227 M. F. Fillat, Arch. Biochem. Biophys., 2014, 546, 41-52.

228 S. Ranjan, S. Yellaboina and A. Ranjan, Crit. Rev. Microbiol., 2006, 32, 69-75.

229 T. Wolf, V. Shelest, N. Nath and E. Shelest, Bioinformatics, 2015, 32, 1138-1143.

230 M. R. Andersen, J. B. Nielsen, A. Klitgaard, L. M. Petersen, M. Zachariasen, T. J. Hansen, L. H. Blicher, C. H. Gotfredsen, T. O. Larsen, K. F. Nielsen and U. H. Mortensen, Proc. Natl. Acad. Sci. U. S. A., 2013, 110, E99-E107.

231 M. Umemura, H. Koike, N. Nagano, T. Ishii, J. Kawano, N. Yamane, I. Kozone, K. Horimoto, K. Shin-ya, K. Asai, J. Yu, J. W. Bennett and M. Machida, PLoS One, 2013, 8, e84028.

232 M. Umemura, H. Koike and M. Machida, Front. Microbiol., 6, 371, DOI: 10.3389/fmicb.2015.00371.

233 T. C. Vesth, J. Brandl and M. R. Andersen, Synthetic and Systems Biotechnology, 2016, 1-8, DOI: 10.1016/ j.synbio.2016.01.002.

234 M. Katz, B. M. Hover and S. F. Brady, J. Ind. Microbiol. Biotechnol., 2015, 43, 1-13.

235 E. W. Schmidt, M. S. Donia, J. A. McIntosh, W. F. Fricke and J. Ravel, J. Nat. Prod., 2012, 75, 295-304.

236 J. C. Kwan, M. S. Donia, A. W. Han, E. Hirose, M. G. Haygood and E. W. Schmidt, Proc. Natl. Acad. Sci. U. S. A., 2012, 109, 20655-20660.

237 S. Sudek, N. B. Lopanik, L. E. Waggoner, M. Hildebrand, C. Anderson, H. Liu, A. Patel, D. H. Sherman and M. G. Haygood, J. Nat. Prod., 2007, 70, 67-74.

238 M. F. Freeman, C. Gurgui, M. J. Helf, B. I. Morinaka, A. R. Uria, N. J. Oldham, H.-G. Sahl, S. Matsunaga and J. Piel, Science, 2012, 338(80), 387-390.

239 A. C. English, S. Richards, Y. Han, M. Wang, V. Vee, J. Qu, X. Qin, D. M. Muzny, J. G. Reid, K. C. Worley and R. A. Gibbs, PLoS One, 2012, 7, e47768.

240 E. Karlsson, A. Lärkeryd, A. Sjödin, M. Forsman and P. Stenberg, Sci. Rep., 2015, 5, 11996. 